\title{
Protective role of taurine against oxidative stress (Review)
}

\author{
STELLA BALIOU $^{1}$, MARIA ADAMAKI $^{1}$, PETROS IOANNOU ${ }^{2}$, AGLAIA PAPPA ${ }^{3}$, MIHALIS I. PANAYIOTIDIS ${ }^{4,5}$, \\ DEMETRIOS A. SPANDIDOS ${ }^{6}$, IOANNIS CHRISTODOULOU ${ }^{1}$, \\ ANTHONY M. KYRIAKOPOULOS ${ }^{7}$ and VASSILIS ZOUMPOURLIS ${ }^{1}$ \\ ${ }^{1}$ National Hellenic Research Foundation, 11635 Athens; ${ }^{2}$ Department of Internal Medicine and \\ Infectious Diseases, University Hospital of Heraklion, 71110 Heraklion; ${ }^{3}$ Department of Molecular Biology \\ and Genetics, Faculty of Health Sciences, Democritus University of Thrace, 68100 Alexandroupolis, Greece; \\ ${ }^{4}$ Department of Cancer Genetics, Therapeutics and Ultrastructural Pathology, The Cyprus Institute of Neurology and Genetics; \\ ${ }^{5}$ The Cyprus School of Molecular Medicine, 2371 Nicosia, Cyprus; ${ }^{6}$ Department of Internal Medicine and Infectious \\ Diseases, University Hospital of Heraklion, 71110 Heraklion; ${ }^{7}$ Nasco AD Biotechnology Laboratory, 18536 Pireus, Greece
}

Received March 29, 2021; Accepted June 3, 2021

DOI: $10.3892 / \mathrm{mmr} .2021 .12242$

\begin{abstract}
Taurine is a fundamental mediator of homeostasis that exerts multiple roles to confer protection against oxidant stress. The development of hypertension, muscle/neuroassociated disorders, hepatic cirrhosis, cardiac dysfunction and ischemia/reperfusion are examples of some injuries that are linked with oxidative stress. The present review gives a comprehensive description of all the underlying mechanisms of taurine, with the aim to explain its anti-oxidant actions. Taurine is regarded as a cytoprotective molecule due to its ability to sustain normal electron transport chain, maintain glutathione stores, upregulate anti-oxidant responses, increase membrane stability, eliminate inflammation and prevent calcium accumulation. In parallel, the synergistic effect of taurine with other potential therapeutic modalities in multiple disorders are highlighted. Apart from the results derived from research findings, the current review bridges the gap between bench and bedside, providing mechanistic insights into the biological activity of taurine that supports its potential therapeutic efficacy in clinic. In the future, further clinical studies are required to support the ameliorative effect of taurine against oxidative stress.
\end{abstract}

\section{Contents}

1. Introduction

2. The role of taurine in homeostasis

Correspondence to: Dr Vassilis Zoumpourlis, National Hellenic Research Foundation, 48 Vasileos Konstantinou Avenue, 11635 Athens, Greece

E-mail:vzub@eie.gr

Key words: taurine, oxidative stress, therapeutics, neurotoxicity, cardiotoxicity, hepatotoxicity
3. The role of taurine against oxidative stress and its underlying molecular mechanisms

4. The beneficial effect of taurine against neuro-associated disorders

5. The anti-oxidant efficacy of taurine against cardiacassociated oxidative stress

6 . The regulatory importance of taurine in ischemia and reperfusion

7. The anti-oxidant efficacy of taurine against muscle-associated disorders

8. The anti-oxidant efficacy of taurine against hepatic-associated stress

9. The anti-oxidant properties of taurine in various toxicmediated insults

10. Conclusions

\section{Introduction}

In 1827, the German professors Friedrich Tiedemann and Leopold Gmelin became the pioneers who isolated the currently known taurine originating from Ox bile and they named it Gallen-Asparagin (1). Later, it was named taurus, after the Latin Bos taurus which means Ox. However, the currently used name (taurine) first appeared in the literature in 1838 by von H. Demarcay (2). Since 1975, the implication of taurine in homeostasis has intrigued the scientific community. Initially, it was reported that taurine deficiency leads to retinal degeneration in cats (3). Diminished taurine levels appeared to be implicated in the development of other pathological conditions, such as cardiomyopathy and developmental defects in many species, therefore suggesting a stringent requirement of taurine for homeostasis (4).

\section{The role of taurine in homeostasis}

Taurine (2-aminoethanesulfonic acid; $\mathrm{NH}_{2} \mathrm{CH}_{2} \mathrm{CH}_{2} \mathrm{SO}_{3} \mathrm{H}$ ) is a non-essential amino acid, not participating in protein synthesis because it is devoid of a carboxyl group. It is not metabolized 
and not involved in gluconeogenesis, thereby not constituting a direct energy source (5). Taurine is an abundant amino acid in many mammalian tissues, including the retina, skeletal muscle, liver, platelets, and leukocytes, exerting many physiological activities, especially in electrically excitable tissues (heart and brain) (6). Since taurine is a sulfonic amino acid with strong acidity and it comprises a zwitterionic amino acid (pK1=1.5, $\mathrm{pK} 2=8.8$ ), it is plausible that it exhibits strong water-soluble and poor lipophilic properties over the physiological $\mathrm{pH}$ range. Even though taurine has low membrane permeability, it passes through the cells via the sodium/chloride dependent taurine transporter (TauT), which is committed to the transport of taurine from the extracellular to the intracellular compartments (7). For this reason, it passes through the lipophilic cellular membrane, and not diffused through, thereby forming a steep concentration gradient. For example, plasma taurine levels range from 40 to $100 \mu \mathrm{M}$, reaching very high concentrations in tissues such as the heart $(30 \mathrm{mM})(8)$, suggesting that plasma taurine levers are 100 -fold lower than in other tissue (7).

The biosynthesis of taurine occurs primarily in the liver, in the kidney, to a smaller extent, in the brain (4) and its content relies on cysteine/methionine metabolism (9). Endogenously, there are two distinct routes of taurine biosynthesis. Firstly, cysteine dioxygenase (CDO) participates in the oxidation of cysteine to cysteine sulfinic acid, where the cysteine sulfinic acid decarboxylase (CSAD) enzyme exerts its action, converting cysteine sulfinic acid to hypotaurine, with the final step being the oxidation of hypotaurine to taurine $(10,11)$. The importance of the CSAD enzyme is confirmed by the death of third generation (G3) CSAD KO (knock-out) mouse models within $24 \mathrm{~h}$ from their birth. Alternatively, cysteine can also be conjugated to coenzyme $\mathrm{A}(\mathrm{CoA})$ and in this way, cysteamine is released during CoA turnover. In this procedure, the 2-aminoethomethiol dioxygenase (ADO) enzyme is actively involved in converting cysteamine to hypotaurine. Notably, the biosynthetic capacity of taurine is high in prenatal life and starts to decline in adulthood, reaching its lowest concentrations in the elderly and in certain pathological conditions (trauma, sepsis). Therefore, taurine biosynthesis does not produce the amount of taurine required for homeostasis and for this reason, exogenous dietary supply of taurine becomes necessary (12). The amount of daily taurine intake is estimated to range from 40 to $400 \mathrm{mg}$ (13) and taurine content depends on the dietary intake of animal/sea origin (12). Characteristically, it has been shown that taurine distribution in vegans is half compared to individuals that follow an omnivore diet (14). Accordingly, the urinary fractional excretion of taurine ranges from 0.5 to $80.0 \%$ based on the diet $(5,15)$.

The physiochemical properties of taurine potentially make it an ideal modulator of various basic processes, including osmoregulation, modulation of protein phosphorylation, calcium ion regulation, anti-oxidant response, membrane stabilization, bile acid conjugation, lipid metabolism, glucose regulation $(16,17)$. The prevailing view regarding the contribution of taurine to bile acid excretion is supported by the notion that taurine conjugates to cholesterol, promoting cholesterol excretion through bile salt formation and fat digestion (18). Furthermore, taurine plays a significant role in reducing lipid peroxidation (LPO) products, thereby protecting cells from tissue damage (19). Notably, taurine is considered to be fundamental in maintaining homeostasis, mainly due to functioning as an intracellular osmolyte in the brain and renal medulla $(5,20)$. It has been reported that taurine is recruited to hypertonic solutions and is released towards lower osmolarity solutions (21). In this way, the osmoregulatory properties of taurine can influence cell volume in tissues. For example, activation of the Fas receptor in Jurkat T lymphocytes is accompanied by high taurine efflux, thereby contributing to cell shrinkage (22). Apart from the potential of taurine to regulate cell volume (23), its osmolytic activity can also contribute to protein folding in the endoplasmic reticulum (ER) (24). For example, taurine stimulates proper protein folding and membrane trafficking of the mutant cystic fibrosis transmembrane conductance regulator (CFTR) protein (delta508 CFTR) in the ER (25). Besides, various reports have also suggested the suppressive impact of taurine on infection, oxidative stress, inflammation, as well as its anti-microbial, its anti-diabetic and its-antitumor activity (26).

The anti-apoptotic nature of taurine underlying its effectiveness. Several examples support that taurine predominantly inhibits apoptosis. Following intestinal ischemia-reperfusion (IR) injury, treatment with taurine appears to abolish mucosal damage and to protect intestinal epithelial cells from apoptosis in IR rats (27). Accordingly, the size of infarction in ischemic-induced brain injury seems to be significantly reduced through the downregulation of pro-apoptotic proteins following treatment with taurine (28). In the case of acute myocardial infarction, exogenous taurine administration seems to confer protection in glucose deprived rat cardiomyocytes from mitochondrial and endoplasmic reticulum stress, by interfering with mitochondria-dependent apoptosis and unfolded protein response (UPR)-related apoptosis (29). In another example, the treatment of UV-treated cells with taurine protect them from oxidative stress, owing to the downregulation of p53-Chk1 pathway (30). This anti-apoptotic property of taurine has also been demonstrated in injuries mediated by toxic insults or drugs, where taurine apparently reverses doxorubicin (DOX)-mediated liver damage (31). In the same context, taurine's anti-apoptotic ability may ameliorate oxidized low-density lipoprotein (oxLDL)-induced cytotoxicity, as shown by experiments in oxLDL exposed human renal proximal tubular epithelial (HK-2) cells (32). The cytoprotective effect of taurine has also been confirmed in osteocytes, by preventing oxidative stress-induced cell death (33). In the same context, taurine exerts a protective effect on hydrogen peroxide $\left(\mathrm{H}_{2} \mathrm{O}_{2}\right)$-mediated damaged osteoblasts, through stimulation of extracellular-signal-regulated kinases (ERK) and $\mathrm{Wnt} / \beta$-catenin pathway (34).

Since taurine is fundamental to certain aspects of normal mammalian development, the positive relationship between taurine loss and various pathological insults is somewhat anticipated. In this frame, pathologies such as mitochondrial myopathy, encephalopathy, lactic acidosis, stroke-like episodes (MELAS) and myoclonic epilepsy and ragged-red fiber syndrome (MERRF) have been attributed to taurine deficiency $(35,36)$, because taurine functions as a substrate for mitochondrial tRNA, thereby protecting mitochondria against excessive superoxide anion $\left(\mathrm{O}_{2}^{-}\right)$generation and ensuring 
normal adenosine triphosphate (ATP) biosynthesis. Recently, taurine administration seems to alleviate negative effects of mitochondrial oxidative stress found in induced pluripotent stem cells (iPSCs) of a patient with MELAS, by normalizing glutathione (GSH) stores and epithelial-mesenchymal transition (EMT) (37).

If one considers that certain pathological lesions are related to low taurine levels (38), it is reasonable to suggest that taurine possibly exhibits a therapeutic effect against cardiovascular diseases, hypercholesterolemia, epileptic seizures, muscular degeneration, Alzheimer's disease, hepatic disorders, alcoholism, and cystic fibrosis.

\section{The role of taurine against oxidative stress and its underlying molecular mechanisms}

Taurine's anti-oxidant activity has been acknowledged for over a decade. On one hand, the high concentration of taurine and its transporter in lymphocytes (39-41), provided significant evidence that taurine was actively involved in the defense against oxidative stress (42). On the other hand, low taurine serum levels have been closely associated with many oxidative stress-mediated pathologies, including hepatic disorders, epilepsy, cardiomyopathy, cystic fibrosis, alcoholism, Alzheimer's disease, growth retardation and retinal degeneration $(43,44)$. When taurine levels decrease, energy metabolism suffers elevations in the NADH/NAD ${ }^{+}$ratio, a process followed by the inhibition of key dehydrogenases (45). The citric acid cycle appears vulnerable to increases in the $\mathrm{NADH} / \mathrm{NAD}^{+}$ratio, as three NADH sensitive enzymes $(\alpha$-ketoglutarate dehydrogenase, isocitrate dehydrogenase, and citrate synthase) are prone to inhibition by elevations in the $\mathrm{NADH} / \mathrm{NAD}^{+}$ratio (45). Experiments using taurine transporter inhibitor ( $\beta$-alanine) have highlighted the inhibition of oxidative metabolism through impaired synthesis of mitochondrial proteins and reduced activity of respiratory chain complexes I and III, which may in turn lead to compromised mitochondrial integrity and decreased ATP production $(46,47)$. We should take into consideration that a decline in electron transport chain (ETC) is mainly mediated through changes in oxidative phosphorylation (OXPHOS), contributing to the development of multiple diseases, despite the NADH/NAD ${ }^{+}$contribution being largely unknown in this process (48). As a consequence, citric acid flux appears to be significantly reduced, leading to inefficient oxidation of endogenous fatty acids and exogenous acetate in the taurine-depleted muscle and favoring the conversion of glucose to lactate for NADH production (45). For example, inhibition of pyruvate dehydrogenase dephosphorylation seems to strengthen its activity, with a concomitant reduction in the expression of fatty acid metabolism-related genes, such as muscle-type carnitine palmitoyl transferase-1 (mCPT-1) (45). The latter makes sense if one considers that fatty acid oxidation genes are under the control of both peroxisome proliferator-activated receptor alpha (PPAR $\alpha)$ and 5' AMP-activated protein kinase (AMPK) and that the expression of the AMPK $\beta 2$ subunit is reduced to a minimum in the skeletal muscle of taurine transporter knock-out (TauTKO) mice [33]. In support of this, AMPK modulates the protein expression of acetyl CoA carboxylase (ACC), which facilitates the transport of long-chain fatty acids into the mitochondria for $\beta$-oxidation (49), thus supporting impaired fatty acid oxidation in taurine-deficient conditions.

A plethora of underlying molecular mechanisms reportedly explain taurine's beneficial action in oxidative stress-associated pathologies (Fig. 1). First of all, taurine is involved in the anti-oxidant defense, as it is conjugated to the tRNA (46). In normal mitochondria, UUG codons of mitochondrial mRNAs are decoded due to the conjugation of taurine with a uridine in the AAU anticodons of tRNA (46). When 5-taurinomethyluridine-tRNA is formed, the UUG codons of mRNA can interact with the AAU anticodons of tRNA (46). This way, following treatment with taurine, decoding of proteins containing UUG codons is enhanced, thereby protecting cells from mitochondrial oxidative stress (50) and mitochondria-dependent apoptosis $(51,52)$. In contrast, when the taurine substrate is lost, the conjugated form of taurine [5 taurinomethyluridine-tRNA] is diminished, causing a significant decline in specific mitochondria-encoded proteins that contain multiple UUG codons, such as NADH-ubiquinone oxidoreductase chain 6 (36). Notably, there is a decrease in respiratory chain complex I subunit biosynthesis, thereby inhibiting the appropriate assembly of subunits required for normal ATP generation $(36,46)$.

In addition to playing a fundamental role within mitochondria, taurine's anti-oxidant activities can take place outside the mitochondria (53). The cytoprotective action of taurine is also evidenced through its potential to detoxify hydrogen peroxide $\left(\mathrm{H}_{2} \mathrm{O}_{2}\right)(54)$, hydroxyl radicals ( $\left.\mathrm{OH}\right)(55)$ and nitric oxide (NO) (12), without acting as the classical scavenger of reactive oxygen species (ROS) formation. For example, when cardiomyocytes were incubated with the taurine transporter antagonist (guanidinoethane sulfonate-GES) or taurine transporter inhibitor ( $\beta$-alanine), mitochondrial oxidative stress increased and was accompanied by an accumulation of superoxide anions $\left(\mathrm{O}_{2}^{-}\right)$, glutathione oxidation (GSSG), and inactivation of anti-oxidant enzymes such as aconitase $(46,50)$. However, treatment with taurine appeared to reverse the oxidative stress by increasing the electron transport chain activity, thereby protecting mitochondria against excessive $\mathrm{O}_{2}^{-}$generation (46). In line with previous findings, the notion that taurine counteracts the side effects of oxidative stress either in mitochondria or in the endoplasmic reticulum following exposure of glucose deprived rat cardiomyocytes to taurine has been confirmed by another research group (29). Specifically, taurine seemed to exert its preventive action via maintaining an intact membrane potential $\left(\Delta \psi_{\mathrm{m}}\right)$, via regulating anti-oxidant enzymes, via suppression of intracellular calcium levels, and through downregulation of UPR-related proteins (29).

Taurine can also act as a cytoprotective molecule against oxidative stress conditions, by decreasing LPO (19) or calcium overload (56-58). For example, in experiments with rats receiving tamoxifen, taurine's anti-oxidant properties have been manifested through attenuation of mitochondrial LPO, thereby protecting the animals from damage (59). Similarly, taurine has been shown to confer protection against oxidative stress through normalization of glutathione (GSH) stores in rats following nicotine administration $(60,61)$. In another case, it has been reported that taurine confers a benefit to NMDA-administered Sprague-Dawley rats bearing retinal injury (62). Indeed, taurine ameliorates retinal oxidative 


\section{Anti-oxidant mechanisms of taurine}

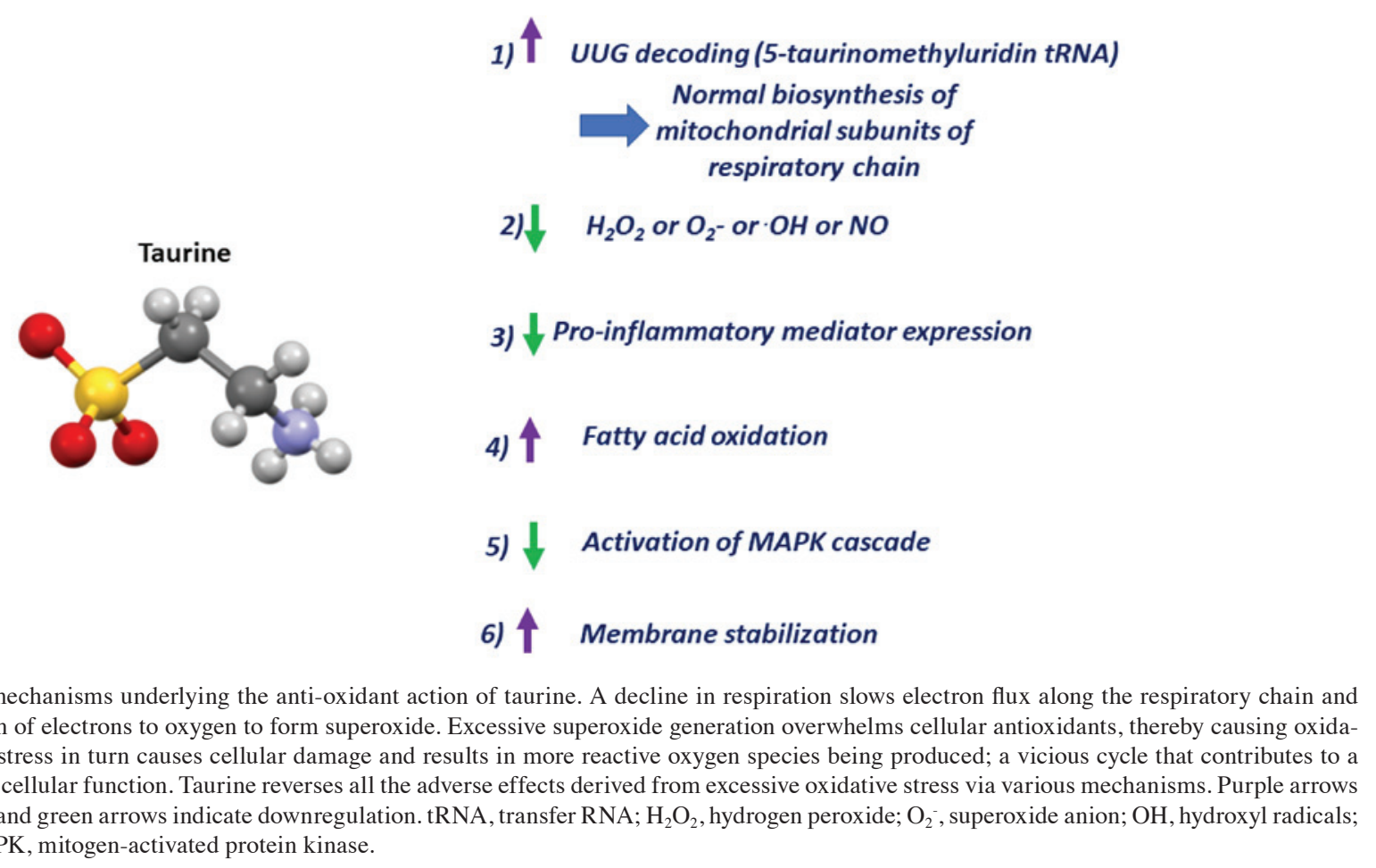

Figure 1. Molecular mechanisms underlying the anti-oxidant action of taurine. A decline in respiration slows electron flux along the respiratory chain and promotes the diversion of electrons to oxygen to form superoxide. Excessive superoxide generation overwhelms cellular antioxidants, thereby causing oxidative stress. Oxidative stress in turn causes cellular damage and results in more reactive oxygen species being produced; a vicious cycle that contributes to a progressive decline in cellular function. Taurine reverses all the adverse effects derived from excessive oxidative stress via various mechanisms. Purple arrows indicate upregulation and green arrows indicate downregulation. tRNA, transfer $\mathrm{RNA} ; \mathrm{H}_{2} \mathrm{O}_{2}$, hydrogen peroxide; $\mathrm{O}_{2}^{-}$, superoxide anion; $\mathrm{OH}$, hydroxyl radicals; NO, nitric oxide; MAPK, mitogen-activated protein kinase.

stress, through augmenting glutathione levels and action of anti-oxidant enzymes (62). Alternatively, taurine acts as an indirect anti-oxidant, as it has the capacity to stabilize the biological membrane and to suppress alterations in membrane permeability caused by oxidative stress factors $(56,63)$. In the same context, the indirect anti-oxidant capacity of taurine is manifested through the formation of taurine derivatives (N-bromotaurine or $\mathrm{N}$-chlorotaurine), which have been produced from the reaction of taurine with either hypobromous acid (HOBr) or hypochlorous acid $(\mathrm{HOCl})(26)$. Taurine derivatives appear to play an important role in protecting phagocytic cells from their self-imposed oxidative injury $(26,64)$.

In addition, taurine modulates the renin-angiotensin system as a defense mechanism against oxidative stress. Several lines of evidence support taurine's indirect anti-oxidant role by its capacity to modulate angiotensin II (Ang II) signaling, through its effect on the nicotinamide adenine dinucleotide phosphate (NADPH) oxidase. Notably, NADPH oxidase is activated following induction of protein kinase $\mathrm{C}$ (PKC) by Ang II signaling and contributes to $\mathrm{O}_{2}^{-}$generation (51). In another case, increased generation of ROS and p38 mitogen-activated protein kinase (MAPK) phosphorylation, as well as increased angiotensin secretion have been observed in renal proximal tubular cells following administration of high glucose $(25 \mathrm{mM})$, all of which are neutralized following taurine administration (65).

Even though taurine has not been tightly associated with inhibiting ROS accumulation, it is believed to exert its action through modulation of anti-oxidant enzymes $(66,67)$. Several reports have supported the notion that taurine enhances the activity of anti-oxidant enzymes (superoxide dismutase-SOD, catalase-CAT, glutathione peroxidase-GPx, glutathione
reductase-GR) (68-70), preserving redox levels and GSH stores (71).

In this review, we outline the oxidative stress conditions which taurine exerts its action in, thereby normalizing the disturbance of redox status. The administration of taurine to patients with oxidative stress-related pathologies (hepatotoxicity; renal disorders; epilepsy; cardiomyopathy; cystic fibrosis; Alzheimer's disease; growth retardation and retinal degeneration) appears to have a beneficial effect, due to its anti-oxidant activity (46). In recent years, taurine has been identified as an attractive protective agent for a broad spectrum of oxidative stress-induced pathologies caused by chemical agents $(72,73)$, toxins $(74,75)$, certain diseases $(76,77)$ and several potential therapeutic options $(74,78,79)$.

\section{The beneficial effect of taurine against neuro-associated disorders}

Taurine seems to be abundant in the central nervous system (80), constituting the major component of electrically excitable tissues (including the brain) and determining the regeneration of the central nervous system (16). Indeed, taurine has been acknowledged as an enhancer of $\mathrm{GABA}_{\mathrm{A}} \mathrm{R}$ and $\mathrm{GABA}_{\mathrm{B}} \mathrm{R}$ receptors (81-84), knowing that gamma-aminobutyric acid (GABA) is the main inhibitory neurotransmitter of the mammalian central nervous system (CNS) (85). When neuronal C6 cells are subjected to morphine-induced oxidative insult and apoptosis, taurine has a positive counteracting effect on oxidative stress, as opposed to anti-oxidant activity conferred by the activation of GABA receptors (86). In this way, taurine has been considered a significant neuromodulator, through its potential to inhibit glutamate transmission (87). 
In brain, taurine has been shown to exert both metabolic and anti-oxidant activity. Firstly, taurine probably serves as a potential anti-oxidant agent in cerebral cell-defense, as shown by the direct interaction of taurine with either $\mathrm{H}_{2} \mathrm{O}_{2}$ or $\mathrm{O}_{2}{ }^{-}$or $\mathrm{OH}$ (55). Secondly, taurine's neuroprotective activity has been explained by its positive effect on carbohydrate metabolism, its inhibitory impact on LPO, its potential to sustain the action of enzymes involved in electron transport chain such as succinate dehydrogenase ( $\mathrm{SDH})$ to normal levels, its capacity to reduce phenomena of either post-ischemic defect or hypercoagulation (88). Thirdly, the function of taurine also contributes to increased hyperpolarizing chloride-mediated conductance and increased membrane stability (89). Fourthly, taurine exerts a strong neuroprotective function through the inhibition of extracellular calcium influx and the outflow of calcium from intracellular pools and through the regulation of neurotransmitters $(57,90)$.

Taurine's neuro-modulating activity is important not only in normal situations, but also in neuronal damage. In neurodegenerative diseases, cell death is caused by glutamate-mediated hyperexcitability and impaired mitochondrial membrane potential (91). Following activation of glutamate receptors, mitochondrial respiratory chain defects along with calcium overload and ROS accumulation seem to be the major routes that are induced, allowing the stimulation of apoptosis $(91,92)$. Among the known signal transduction pathways related to apoptosis is the activation of UPR pathways during ER stress, which leads to the activation of caspase-12, CHOP (C/EBP homologous protein) and c-Jun NH-terminal kinase (JNK) proteins $(93,94)$. In this context, taurine can function as a repair system against glutamate toxicity by inhibiting ER stress-mediated apoptosis and calcium overload $(89,95)$. Interestingly, taurine seems to attenuate peroxisomal oxidative malfunction, by reducing malondialdehyde (MDA) levels, expression levels of peroxisomal membrane proteins and by upregulating anti-oxidant enzymes in rats injected intracerebroventricularly with A $\beta$ 1-42 (96). Similarly, taurine's protective mode against glutamate-induced oxidative neurotoxicity appears to happen through an increase in heme oxygenase-1 (HO-1) expression in HT22 mouse hippocampal neuronal cells (97). In particular, taurine has been shown to upregulate the transactivation rate of nuclear factor-E2-related factor 2 (Nrf2), which is the key transcription factor for HO-1 expression (97). Use of p38 inhibitors has confirmed that taurine-mediated HO-1 expression is caused by the induction of the p38 signaling cascade (97). In addition to affecting the HO-1 expression, taurine has also been documented to enhance anti-oxidant responses in many other cases of neurotoxicity. Interestingly, taurine administration appears to increase the action of anti-oxidant enzymes (SOD, CAT, and GPx), in an attempt to overcome morphine-induced oxidative stress (86) and hexabromocyclododecane (HBCD)-induced cytotoxicity (98). In perfluorooctane sulfonate (PFOS)-induced neurotoxicity, taurine has been shown to exert potent anti-oxidant properties through its ROS-scavenging capacity in PC12 cells, originating from the embryonic neural crest (98).

In keeping with the anti-oxidant role of taurine, it has been reported that taurine can ameliorate neuro-associated changes arising in the cerebrum, following exposure to toxins such as arsenic (99-101). For example, taurine can preserve the viability of arsenite-exposed primary cortical neurons, through upregulation of PI3K/Akt pathway (102). Taurine emerges as a key protective factor against the activation of autophagy in the cerebrum of arsenic oxidoarsenous trioxide $\left(\mathrm{As}_{2} \mathrm{O}_{3}\right)$-intoxicated mice (103), given that the self-degradation process of autophagy is the main cause of arsenic-induced neurotoxicity $(104,105)$. Specifically, the expression levels of microtubule-associated protein light chain 3B (LC3II) and its bound p62 protein are reduced in cerebral neuronal cells of $\mathrm{As}_{2} \mathrm{O}_{3}$-intoxicated mice following taurine administration, thereby highlighting taurine's neuroprotective role (103). If one considers that the Nrf2 transcription factor is transactivated following oxidative stress so as to stimulate autophagic flux $(106,107)$, it is possible that taurine can attenuate the expression levels of $\mathrm{Nrf} 2$ transcription factor in the cerebrum of $\mathrm{As}_{2} \mathrm{O}_{3}$-exposed mice (103). Accordingly, it has been reported that taurine causes a marked decline of autophagy marker such as LC3II, following methamphetamine $(\mathrm{METH})$ and taurine administration in PC12 cells, originating from the embryonic neural crest (108).

The beneficial effect of taurine on stroke-related injury has also been examined in humans (109). The advantageous effect of taurine on stroke events has been attributed to its anti-oxidant and anti-inflammatory properties. Specifically, taurine was shown to enhance anti-oxidant enzyme activity by reducing $\mathrm{O}_{2}^{-}$production, thereby improving mitochondrial function in traumatic/ischemic brain injury (TBI) (110). Such evidence is in agreement with the involvement of taurine in mitochondrial protein synthesis and increased ETC activity (111). In another case, Lotocki et al (112) demonstrated that expression levels of pro-inflammatory cytokines (TNF- $\alpha$, IL-6, IL-1 $\alpha$ and IL-1 $\beta$ ) were substantially reduced in both spinal cord injury (SCI) and traumatic/ischemic brain injury (TBI), following taurine treatment (113), proving taurine's anti-inflammatory properties in injured brain cells (113). Accordingly, the anti-oxidant and the anti-inflammatory properties of taurine account for its regenerative and protective capacity in TBI cells (114). Furthermore, taurine levels have been increased as a defense mechanism against excitotoxicity and hypoxia (115). Specifically, taurine has been shown to ameliorate damage in rat cortical brain slices subjected to a hypoxia-reoxygenation insult by suppressing brain cell swelling (116); this is probably due to taurine's inhibitory action on the substrate of NADH oxidase $(45,117)$, via which it mediates the downregulation of Nox2/Nox4 (NADH oxidase isoforms) (118).

\section{The anti-oxidant efficacy of taurine against cardiac- associated oxidative stress}

Initial efforts highlighted that a taurine-deficient diet causes dilated cardiomyopathy in the cat and fox $(119,120)$. Later on, it was proposed that taurine ablation mediated by either taurine transporter inhibitor $(\beta$-alanine) or taurine transporter antagonist [guanidinoethane sulfonate (GES)] leads to cardiac injuries in mice or rats (121). Following these observations, it was proposed that low plasma taurine is associated with myocardial failure (119). The hallmarks of taurine deficiency-induced cardiomyopathy are as follows: Remodeling of ventricular cardiomyocytes, ultrastructural damages of myofilament and mitochondria, and overexpression of markers 
of heart failure, such as atrial natriuretic peptide (ANP), brain natriuretic peptide (BNP) and beta-myosin heavy chain (MYH7) $(122,123)$. In a clinical setting, it has been recorded that patients with chronic congestive heart failure have twice the amount of taurine as compared to matched controls, highlighting an inconsistency between the results obtained from patients and the results derived from inhibitor-mediated taurine loss (124).

Over 50 percent of the total free amino acid pool in the heart is reportedly occupied by taurine (125), which appears to have a positive inotropic action on cardiac tissue (126) and to lower high blood pressure $(127,128)$. Taurine protects cardiomyocytes from damage mediated by either excessive or inadequate calcium ion levels due to its regulatory effect on the activity of the voltage-dependent calcium and sodium channels (129). At the same time, taurine acts on many other ion channels and transporters, even though its mechanism of action is not quite specific (14). Importantly, it has also been suggested that taurine stabilizes membrane potential through its interference with membrane-bound $\mathrm{Na}^{+} \mathrm{K}^{+} \mathrm{ATPase}$ (130).

The inhibitory effect of taurine on atherogenesis. Considering the multiple functions of taurine, its administration appears to cause a regression of atherogenesis through several possible mechanisms. First of all, in the majority of studies, taurine administration caused a marked decline in cholesterol levels in atherogenic animals (131-133). During the regression period of atherogenesis, hepatic cholesterol levels were rapidly decreased in taurine treated animals, due to taurine's ability to accelerate the degradation of cholesterol, as indicated by the increase in cholesterol 7 $\alpha$-hydroxylase (CYP7A1) activity (132-135). At the same time, taurine administration inhibited hepatic biosynthesis of cholesterol esters and triglycerides through the decreased activity of 3-hydroxy-3-methylglutaryl CoA reductase (HMG-CoA reductase) (136). Since the latter plays a determinant role in the assembly of lipoproteins in the endoplasmic reticulum, it was considered that taurine abrogated the assembly and secretion of lipoproteins containing the apolipoprotein B100, the primary structural constituent of both LDL and VLDL $(132,137)$. In another study, taurine prevented the passage of glucose-induced and oxidized LDL (oxLDL)-induced endothelial cells in vascular tissue, thereby alleviating the risk of atherosclerosis (138). In support of the above, taurine appeared to attenuate atherogenesis by importing reduced levels of oxidized LDL, through downregulation of lectin-like oxidized low-density lipoprotein LDL receptor-1 (LOX-1) (139). Indeed, taurine's cholesterol-lowering effect has been analyzed both on experimental animal models with atherosclerosis and on animal models with inducible hypercholesterolemia $(131,140,141)$. In the case of hypercholesterolemia induced by the high cholesterol/sodium and cholate diet, serum cholesterol and lipid levels are reduced following taurine supplementation, given that cholate is known to increase cholesterol absorption (142). In the same model, taurine appears to mediate its action via an increase of CYP7A1 mRNA levels (142). The latter is considered to be the rate-controlling enzyme for the catabolic conversion of hepatic cholesterol to bile acids for subsequent elimination in the feces. On the contrary, taurine does not appear to exert an effect in cases of endogenous hypercholesterolemia that are caused by phenobarbital (PB) or by polychlorinated biphenyl (PCB) $(143,144)$.

The ameliorative action of taurine against endothelial dysfunction. In addition, it has been suggested that taurine protects endothelial cells from the homocysteine-induced ER stress and apoptosis, and from toxicity through the inhibition of hyperhomocysteinemia (145). Since both hyperglycemia and hyperhomocysteinemia can be characteristics of oxidative stress, resulting from the accumulation of asymmetric dimethylarginine (ADMA), which is a major endogenous nitric oxide synthase inhibitor (146). In another case, taurine supplementation has been shown to confer benefit against oxLDL mediated endothelial dysfunction, as shown by in vitro and in vivo experiments (146). In the in vitro setting, administration of taurine ( 1 or $5 \mathrm{microg} / \mathrm{ml}$ ) has been shown to alleviate signs of oxidative stress in human umbilical vein endothelial cells (HUVECs) treated with oxLDL, as demonstrated by reduced levels of lactate dehydrogenase (LDH), tumor necrosis factor-a (TNF- $\alpha$ ), MDA and NO (146). In the in vivo setting, taurine supplementation in endothelial cells treated with oxLDL ( 60 or $180 \mathrm{mg} / \mathrm{kg}$ ) has been demonstrated to contribute to endothelium-dependent vasorelaxation, through the inhibition of NO (146). Accordingly, Elvevoll et al have suggested that taurine acts synergistically with $\mathrm{n}-3$ fatty acid supplementation, enhancing the beneficial effects of fatty acids on total cholesterol, LDL cholesterol and triglycerides in human subjects (147). In another study, taurine has been proved to play an important role in ameliorating endothelial dysfunction via protein kinase $\mathrm{B}(\mathrm{Akt})$ and extracellular-signal-regulated kinase (ERK) signal transduction cascades, without inducing vascular inflammation and permeability in vitro and in vivo (148). Recently, Katakawa et al explained why humans on a diet that included taurine and magnesium supplementation are characterized by a minimal risk of developing atherogenesis due to a decrease in oxidative stress and improved endothelial function (149).

An increasing amount of evidence highlights the cytoprotective properties of taurine, which ameliorate the cardiac damage induced by various toxins $(74,75)$, by attenuating mitochondrial dysfunction $(150,151)$. For example, it has been suggested that taurine can overcome cardiac dysfunction mediated by either methionine or doxorubicin (DOX), by reducing ROS generation or intracellular calcium overload, respectively $(150,151)$. In addition, it has been reported that taurine exerts a protective effect against arsenic-induced cardiac oxidative stress, playing a pivotal role in modulating ROS production, calcium overload and apoptotic cell death (151), taking into consideration that taurine ameliorates arsenic-induced neuro-associated changes in the cerebrum through the downregulation of autophagy (103). In this case, it has been highlighted that downregulation of $\mathrm{p} 38$ MAPK and JNK signaling pathways appear to be the main mechanisms underlying the protective action of taurine, ultimately attenuating nuclear factor- $\mathrm{\kappa B}(\mathrm{NF}-\kappa \mathrm{B})$ transcription and blocking the apoptotic signaling pathway (151). In the same context, it has been mentioned that an important problem of cirrhosis is the heart injury, which can be assimilated with the use of bile duct ligated (BDL) animals. When taurine is administered to BDL animals for 42 consecutive 
days, it can rescue heart injury, by restoring mitochondrial function in the myocardium of animals (152). Taurine can ameliorate heart failure, by increasing energy expenditure $\left(\mathrm{NAD}^{+} / \mathrm{NADH}\right)$ and by interfering with acetylation of $\mathrm{p} 53$ transcription factor (153).

The beneficial effect of taurine has also been confirmed in experimental genetically modified animal models of oxidative stress. For example, in methionine sulfoxide reductase A gene knockout mice $\left(\mathrm{MsrA}^{-/}\right)$exposed to $\mathrm{H}_{2} \mathrm{O}_{2}$ insult that are characterized by mitochondrial dysfunction in the myocardium, taurine has been shown to protect $\mathrm{MsrA}^{-/-}$cardiac myocytes, exposed to $\mathrm{H}_{2} \mathrm{O}_{2}$ insult. Specifically, cardiac disturbance was determined in 8-months old $\mathrm{MsrA}^{-/}$mice through a marked decline of ejection fraction (EF) and fraction shortening (FS), as compared to control mice. Prolonged administration of taurine (5 months) to $\mathrm{MsrA}^{-/}$mice exposed to $\mathrm{H}_{2} \mathrm{O}_{2}$ insult was shown to improve mitochondrial dysfunction, thereby suggesting a protective role for taurine in $\mathrm{MsrA}^{-/}$cardiac myocytes from protein oxidation. Nonetheless, taurine treatment on its own did not appear to have a significant impact on the oxidative status of $\mathrm{MsrA}^{-/}$hearts (154). Similarly, taurine favorably contributes to normal cardiac function, as shown by the reduction of LDH and uric acid, which constitute serum markers of cardiac disorders (155) and by the inhibition of enzymes degrading extracellular matrix such as matrix metalloproteinase-2 (MMP-2) (156). As a result, taurine exerts its beneficial action against heart failure, through modulation of calcium homeostasis, regression of atherogenesis, its interaction with endothelial cells. Indeed, taurine exerts its multiple actions by modulating signaling pathways to restore cardiac tissue taurine levels, to ameliorate potential cardiac abnormalities.

\section{The regulatory importance of taurine in ischemia and reperfusion}

Numerous studies have reported that the harmful consequences of ischemic oxidative stress include the following: i) Reduced myocardial anti-oxidants, ii) disturbed mitochondrial membrane potential $\left(\Delta \psi_{\mathrm{m}}\right)$, and iii) superoxide anion $\left(\mathrm{O}_{2}{ }^{-}\right)$accumulation $(47,157)$. Taurine molecule is one of the several factors that have been proposed to alleviate symptoms of ischemia-reperfusion (110). In particular, several investigators have suggested that taurine could be incorporated to cardioplegic solutions (158) or uploaded to the donor's hearts before transplantation $(159,160)$. Taurine's therapeutic effectiveness against ischemia-reperfusion injury and cardiovascular diseases, including congestive heart failure, has been well-demonstrated. For example, oral taurine supplementation ( $3 \mathrm{mg} / \mathrm{kg}$ ) has been shown to improve systolic left ventricular function within the space of 6 weeks, compared to treatment with coenzyme Q10 in 17 patients with congestive heart failure. Consistent with clinical trials, animal studies have also produced similar results. For example, taurine perfusion has been shown to improve oxidative injury (i.e. LPO), ventricular function, and infarct size during reperfusion in isolated rat hearts (161).

Excessive accumulation of calcium $\left(\mathrm{Ca}^{2+}\right)$ is cytotoxic to the heart (162). Calcium overload is not only capable of the induction of proteases and lipases, but it also facilitates mitochondrial permeability transition, eventually causing the release of pro-apoptotic factors from the mitochondria to the cytoplasm $(52,163)$. It has been shown that the taurine transporter uptakes lower taurine concentrations during an ischemia-reperfusion insult, causing the respective loss of intracellular sodium $\left(\mathrm{Na}^{+}\right)$(164). It should be taken into consideration that a vicious cycle is observed between sodium and calcium, and more sodium is available for calcium entry via the $\mathrm{Na}^{+} / \mathrm{Ca}^{2+}$ exchanger, exacerbating calcium overload (165). Firstly, taurine exerts great anti-oxidant activity by preventing calcium overload during reperfusion (166-168) and by protecting the myocardium from LPO products (169). In particular, taurine has also been shown to regulate the activity of the sarcoplasmic reticulum (SR) $\mathrm{Ca}^{2+}$ ATPase, given that ATPase retains cytosolic calcium to normal levels, promoting cellular calcium homeostasis (170). Even though the effect of taurine on protein phosphorylation remains to be stablished, enough experimental evidence has been obtained to suggest that taurine loss induces the reduction of $\mathrm{SR} \mathrm{Ca}^{2+} \mathrm{ATPase}$ activity and the phosphorylation state of phospholamban, which is accompanied by delayed myocardial relaxation and ROS accumulation $(46,76,165)$. This positive effect on ischemic oxidative stress relies on reducing osmotic stress and calcium overload $(165,171)$. As a result, both the systolic and diastolic heart function are disturbed, as $\mathrm{SR} \mathrm{Ca}^{2+}$ pump activity is reduced to a minimum.

Secondly, taurine contributes to the inhibition of $\mathrm{K}^{+}$-ATP channels and slows down the decrease of intracellular ATP in ischemic hearts (172). The suppressive effect of taurine against the opening of $\mathrm{K}^{+}$-ATP channels is cytoprotective, not only in terms of ATP content but also in the regulation of calcium homeostasis. In this regard, taurine exerts protective action against ischemia-reperfusion injury through regulation of potassium efflux, which in turn modulates the influx of calcium ions, thereby leading to the sustenance of the ATP content $(172,173)$. Notably, it seems that administration of taurine can reverse ischemic oxidative stress through its ability to reduce ROS formation, by the mitochondrial electron transport chain and through its anti-inflammatory activity with the formation of $\mathrm{N}$-chlorotaurine (174).

Thirdly, taurine can serve either as anti-apoptotic or as an apoptotic agent in various circumstances. On one hand, taurine appears to be effective in inhibiting myocardial ischemia due to the induction of apoptosis through interference with the apoptosome, which is comprised of the apoptotic protease activating factor-1 (Apaf-1)/caspase-9 and the Akt/caspase-9 pathway (175). On the other hand, inhibition of apoptosis has also been identified as the underlying mechanism by which cardiomyocytes continue their proliferation, neutralizing the NADPH oxidase, and calpain activation (176). In the same context, taurine has been found to act as an anti-apoptotic agent in cardiomyocytes subjected to experimental ischemia-reperfusion (108). Of particular interest has been the ability of taurine to maintain energy levels and to preserve myocardium homeostasis against DNA damage signals before or during ischemia (110).

In addition, ischemia-reperfusion has emerged as a potential challenge in patients undergoing ovarian transplantation. Taurine seems to exert its beneficial effect, circumventing the ischemia-reperfusion, by increasing angiogenesis and by hindering apoptosis as well as oxidative stress (177). 
Overall, one of the most important actions of taurine against ischemia is its regulatory impact on intracellular calcium levels and its anti-oxidant activity. Primarily, taurine counteracts ischemic oxidative damage by attenuating intracellular calcium levels (166-168). Intriguingly, taurine loss contributes to the activation of $\mathrm{K}^{+}$-ATP channels and slows down the decrease of intracellular ATP levels in ischemic hearts (172). Also, taurine's anti-oxidant activity is mediated by the attenuation of xanthine oxidase and the ROS-forming inflammatory reaction, thus limiting ROS synthesis via complex I of ETC (174).

\section{The anti-oxidant efficacy of taurine against muscle- associated disorders}

Skeletal muscle is one of the tissues that accumulates the higher amount of the body's taurine, through the action of taurine transporter (TauT). Primarily, the significance of taurine in skeletal muscle emerged through its deficiency in $\mathrm{TauT}^{-/}$mice. In particular, those taurine deficient mice presented with a $90 \%$ decrease in taurine content, showing abnormalities of muscle structure. The impaired mitochondrial function and disturbed fatty acid oxidation accounted for the phenotype of skeletal muscle in TauT $^{/-}$mice (178). As expected, the high concentration of taurine is important for normal muscle performance and excitation-contraction coupling. The main action of taurine in skeletal muscle appears to be the regulation of mitochondrial protein synthesis, which is achieved by increasing electron transport chain activity and by preventing excessive superoxide anion $\left(\mathrm{O}_{2}^{-}\right)$formation, thereby establishing normal adenosine triphosphate (ATP) biosynthesis (46). Apart from the regulatory effect of taurine on mitochondrial function and respiratory chain, it has also been reported that taurine facilitates calcium homeostasis and displays strong anti-oxidant properties (179). Specifically, taurine seems to be significantly involved in the regulation of calcium release from the sarcoplasmic reticulum (SR) and to improve the sensitivity of contractile elements to intracellular calcium levels (179). This way, contractile properties and force production of skeletal muscle are regulated in a taurine-dependent manner (179). In support of this, several studies have evidenced the contribution of taurine to calcium homeostasis. For example, administration of $20 \mathrm{mM}$ taurine in isolated skinned myofibers accounted for the excess amount of calcium into SR, thus enabling for the greater depolarization-mediated contraction of myofibers (179). The effects of long-term taurine administration were similar to its short-term supplementation (180). When both type I and II human myofibers were exposed to 10-20 mM taurine in the long-term, there was a remarkable increase in calcium uptake, thereby leading to augmented sensitivity of contractile apparatus of myofibers to calcium (181). Accordingly, high levels of taurine have been shown to promote calcium homeostasis by inducing active re-absorption by the SR (124) and by controlling ion channels in the skeletal muscle cells (182).

It is important to note that taurine is concentrated in the skeletal muscle against gradient, not only due to its effect on calcium, but also on chloride channels. The contribution of taurine to the regulation of chloride channels has been highlighted in taurine-deficient conditions, caused by taurine transporter antagonist or inhibitor, in which taurine elimination accounted for reduced chloride conductance $(\mathrm{gCl})$, accompanied by the increased sarcolemmal excitability (183). These results acquire additional significance, if one considers that resting $\mathrm{gCl}$ plays a pivotal role in total membrane conductance of sarcolemma and maintains the sarcolemmal electrical stability by shunting the depolarization-driven potassium accumulation (184).

The positive effect of taurine on muscle during intense and prolonged exercise. Several reports have highlighted a favorable effect of taurine on animal skeletal muscle during steer exercise. Intense and prolonged exercise is believed to reduce rat skeletal muscle taurine levels, by exerting a negative effect on skeletal muscle performance $(185,186)$. Taurine-treated rats display a normal taurine content during exercise and enhanced endurance until the running time is increased to exhaustion, as compared to control rats (187). Apart from the anti-oxidant role of taurine, taurine administration has been shown to alter hepatic glucose tolerance, to exert a stimulatory effect on hepatic gluconeogenesis and to enhance endurance time during exercise (188).

When taurine is supplemented in the long-term, its effects on skeletal muscle are strengthened during exercise, as evidenced by subsequent taurine-mediated changes in the metabolism and inflammation. For example, long-term administration of taurine (5\% taurine in drinking water for 12 months) appeared to exert a positive effect on glucose tolerance and to inhibit triglyceride (TG) deposition, reinforcing the glucose uptake in skeletal muscle post-exercise (189). This was suggested to have occurred through the activation of $5^{\prime}$ AMP-activated protein kinase (AMPK) and the reduction of total AMPK protein content in the gastrocnemius (GAST) muscle of ob/ob mice (189), thereby favoring an increase in carbohydrate oxidation, rather than an increase in fatty acid oxidation. In another study, taurine supplementation returned taurine levels to normal rates and prevented the increase of plasma creatinine and TG levels under prolonged exercise-induced muscle damage (190). Taurine was proved to minimize oxidative stress by reducing the cytosolic content of LDH and creatine kinase (CK) (191). Also, the long-term administration of taurine has been evidenced to be beneficial against in vivo eccentric exercise damage, as shown in rats (192). The mechanism underlying the protective mode of taurine was based on the inhibition of either protein carbonylated (PC) content or oxidized thiols, without modulating the activities of anti-oxidant enzymes (192).

Besides, the well-established anti-inflammatory properties of taurine were identified in the muscles of rats under an intensive exercise protocol, where it seemed to contribute to muscle repair, through its capacity to alleviate the signs of inflammation (193). Specifically, TNF- $\alpha$ and IL-6 appeared to be preferentially reduced in the stromal cells of skeletal muscle, accompanied by a strong reduction of accumulated CD68 signal intensities within the muscle fibers (194). In the same context, taurine has been proved to confer benefit against nitrosative inflammation and muscle DNA damage during strenuous exercise, through interference with inducible nitric oxide synthase (iNOS) (195). Notably, the adverse effects of exercise in the form of injury have mainly been observed in 
type I muscle fibers which are composed of a higher number of mitochondria in comparison to type II muscle fibers (196); therefore, type I muscle fibers appear to generate higher levels of free radicals during exercise, as well as at rest, due to greater polyunsaturated fatty acid (PUFAs) gene expression, which renders them more susceptible to lipid peroxidation (LPO) and other types of oxidative damage $(197,198)$.

In addition to the above, a treatment scheme including a combination of caffeine and taurine over 2 weeks seemed to increase the run time of mice on a treadmill, thereby resulting in increased endurance time of mice during exercise due to diminished muscle lactate levels (199). Indeed, the combination scheme (taurine and caffeine) displayed ergogenic properties, whilst also enhancing muscle power output (199). Accordingly, another combination scheme including taurine and fish oil has been shown to enhance fatty acid oxidation by upregulating the activity of acyl-CoA oxidase (ACO), which is regarded as the rate-limiting enzyme of peroxisomal fatty acid $\beta$-oxidation (200). The same combination scheme has also been shown to improve glycolysis, via increasing GLUT4 distribution, thereby facilitating diffusion from circulating glucose (200). However, taurine supplemented in combination with branched-chain amino acids (BCAA) (9.6 grammars of BCAA and 6 grammars of taurine/day) did not seem to have a direct impact on the skeletal muscle of men following intense exercise, but it seemed to reduce the serum levels of muscle damage markers, such as $\mathrm{LDH}$, lactate aldolase and 8-hydroxydeoxyguanosine (8-OHdG) (201).

The effect of taurine on human skeletal muscle. Even though taurine supplementation has been proved to be very successful in alleviating signs of muscle injury in various animal models, its effect on human skeletal muscle has not been completely elucidated. Relatively high doses of taurine supplementation (1.66 grammars) have been shown to increase plasma taurine levels by 15 -fold (from $50 \mathrm{mmol} / 1$ to over $750 \mathrm{mmol} / \mathrm{l}$ ) within $2 \mathrm{~h}$, and high plasma taurine levels of $350 \mathrm{mmol} / \mathrm{l}$ can be sustained for $4 \mathrm{~h}$ (202). At this point, subsequent acute dietary supplementation of taurine (1.66 grammars) can accelerate the concentration of taurine in the plasma to $1,000 \mathrm{mmol} / \mathrm{l}$ within the space of one hour, and then it follows a rapid falling trend, reaching the $150 \mathrm{mmol} / \mathrm{l}$ within $4 \mathrm{~h}$ (202). Besides, acute dietary supplementation of taurine increases plasma taurine levels in a way similar to that caused by creatinine supplementation $(190,203)$.

When taurine was given in an acute manner (i.e., in short time intervals), researchers examined its impact on endurance time in the skeletal muscle of various trained subjects. Acute dietary supplementation of taurine (1.66 grammars), one hour before a 90 min submaximal cycle did not appear to affect time trial performance in human subjects, and prolonged supplementation of taurine ( 5 grammars/day for 7 days) did not appear to have any effect on human skeletal muscle (202). Experiments in well-trained cyclists showed the high dietary intake of taurine (204). In this context, Rutherford et al supported that taurine exerts its action through the activation of adenyl cyclase, by increasing cyclic adenosine monophosphate (cAMP) and therefore by increasing lipolysis and subsequently fat oxidation (204). In particular, fat oxidation was increased by a rate of $16 \%$, when taurine was given in conjunction with a
90 min submaximal exercise period (204). Similar results were obtained with acute dietary supplementation of $1 \mathrm{~g}$ taurine $2 \mathrm{~h}$ before a $3 \mathrm{~km}$ treadmill exercise in yet another study (205). No alterations were observed in parameters such as heart rate, perceived exertion, oxygen consumption, or blood lactate concentrations, whereas skeletal muscle performance was slightly improved (205).

At molecular setting, taurine has been shown to overcome oxidative stress induced by intense exercise in young men, through alterations in calcium homeostasis. This mechanism of action is based on increasing intracellular calcium levels released from the SR and therefore makes contractile filaments more vulnerable to intracellular calcium levels (179). The positive effect of taurine supplementation on calcium homeostasis following intense exercise also leads to increased muscle strength, reduced muscle soreness, as well as decreased serum LDH activity, serum creatine kinase activity, PC content and LPO (206). Nonetheless, taurine does not seem to affect the expression levels of pro-inflammatory markers [TNF- $\alpha, \mathrm{IL}-1 \mathrm{~b}$, IL-10] in the human skeletal muscle (206). On the contrary, clinical studies recently highlighted that taurine exerts an incremental effect on intracellular calcium levels excreted by the SR into either type of fiber, without altering maximum calcium rates (181).

Interestingly, taurine supplementation seems very promising in improving vascular endothelial function following a high-intensity exercise. Specifically, 29 healthy men were divided into two groups: Taurine-treated and taurine-untreated; taurine-treated men received 6 grammars of taurine for 2 weeks prior to exercise and for 3 days following exercise; taurine supplementation improved endothelial function, as demonstrated by increasing relative and absolute values of brachial artery flow-mediated dilation (FMD), whilst also preventing a resistance exercise-induced arterial stiffness (207).

Taurine has been shown to minimize oxidative stress and muscle damage in humans; taurine administered to 11 sedentary young men at 2 grammars per 3 times per 7 days leads to a marked decline of white blood cell DNA migration $24 \mathrm{~h}$ after an exhaustive maximal $\mathrm{VO}_{2}$ test (208). Even though taurine supplementation appeared to be effective in reducing LPO before exercise, it did not seem to significantly affect serum thiobarbituric-acid reactive substance (TBARS) levels after exercise (208).

Besides, taurine administration seems to ameliorate the side effects of exercise in older women, namely the cognitive dysfunction and neurodegeneration, by reducing the myeloperoxidase (MPO) activity (209).

Equally important seems to be the notion that taurine seems to be involved in the regeneration of muscle fibers in patients with muscle atrophy (210). Specifically, taurine improves the dexmedetomidine-induced muscle atrophy in $\mathrm{C} 2 \mathrm{C} 12$ myocytes by keeping the expression of atrophy-associated genes to normal levels $(211,212)$. However, taurine does not seem to exert any positive effect on skeletal muscle atrophy under pathological conditions $(185,211)$. On a similar basis, taurine has been reported to affect the progression of duchenne muscular dystrophy (DMD) (213). In DMD patients, expression of the dystrophin gene is impaired, resulting in the replacement of skeletal muscle with nonfunctional fibrotic tissue and in high urinary excretion levels of taurine (213). Despite the 
reported therapeutic effectiveness of glucocorticoids against DMD, their use is limited due to related adverse effects. In vivo experiments have demonstrated that taurine enhances the effects of classical glucocorticoid [ $\alpha$-methyl-prednisolone (PDN)] in the fast-twitch muscle on MDX mice, by attenuating the overactivity of voltage-independent cation channels and by preserving calcium homeostasis in extensor digitorum longus (EDL) myofibrils and alleviating signs of DMD (214).

\section{The anti-oxidant efficacy of taurine against hepatic- associated stress}

Oxidative stress in hepatocytes is closely associated with hepatic damage (215). Taurine is essential for liver homeostasis and taurine deficiency in hepatocytes causes severe hepatic damage, followed by compensatory hepatocyte proliferation (216). The phenotype of $\mathrm{TauT}^{-/}$mice is characterized by various manifestations of hepatic dysfunction, hepatitis, and liver fibrosis, all of which are mediated by impaired mitochondrial function and inefficient control of the respiratory chain (216). Interestingly, taurine deficiency appears to have a profound effect on Kupffer and sinusoidal endothelial cells but not in parenchymal cells (216).

Taurine has emerged as an attractive therapeutic agent against liver injury as it is actively involved in the reduction of hepatic oxidative burst, which is accompanied by a remarkable increase in anti-oxidant enzymes and by attenuation of inflammatory injury (217). In cases where ethanol is the cause of hepatic oxidative stress, hepatic MDA levels are decreased, whereas the activity of hepatic superoxide dismutase (SOD) is significantly increased, following taurine treatment (217). Similarly, taurine has been considered as a palliative agent to combat renal and hepatic oxidative stress of alcohol-supplemented mice, through its advantageous effect on GSH, MDA levels and anti-oxidant enzymes (218). Taurine has also been shown to limit the possibility of hepatic steatosis, by reducing TNF- $\alpha$ expression levels and by increasing fatty acid oxidation through activation of carnitine palmitoyltransferase 1a (CPT1a) (217). This is of utmost importance if one considers that peroxisome proliferator-activated receptor alpha (PPAR $\alpha)$ and 5'AMP-activated protein kinase (AMPK) are essential for the regulation of genes involved in the oxidation of long-chain fatty acids (glutathione peroxidase 3 and carnitine palmitoyl transferase 2) and that their levels decline in cases of impaired fatty acid oxidation, such as in the skeletal muscle of TauT ${ }^{-1}$ mice (178). In a rat model of chronic alcohol consumption, taurine has been shown to impair lipogenesis, lymphocyte infiltration as well as iNOS, C-reactive protein (CRP), and inflammatory cytokine expression through TLR4/MyD88 signal transduction, proving its anti-inflammatory properties (219). Accordingly, taurine ameliorates hepatic steatosis, by reducing ROS, lipid accumulation and preserving mitochondrial membrane potential (220). In an iron-overload murine model of oxidative stress, which mimics features of chronic liver diseases (such as alcoholic liver disease and chronic viral hepatitis), taurine has been shown to reduce the accumulation of ROS, thereby exhibiting strong anti-oxidant activity (221). In another experimental setting, administration of $2 \%$ taurine $(2 / 100 \mathrm{~g}$ diet) to rats fed a $50 \%$ calcium-deficient diet, has been shown to inhibit LPO in the liver, as compared to control rats (222). This makes sense if one considers that calcium is a crucial component of cholesterol and lipid metabolism and that taurine has been shown to counteract the effects of oxidative stress by regulating both calcium and lipid homeostasis (222). In other case, rats supplemented with a $5 \%$ taurine diet demonstrated a reduction in their visceral fat weight, because of reduced cholesterol levels, downregulation of fatty acid synthase (FAS) and upregulation of carnitine palmitoyltransferase $1 \alpha$ (CPT1a) (30). In another case, it has been substantiated that taurine provides protection against hepatorenal injury caused by fipronil (FPN), a commonly used pesticide (223). In FPN-induced hepatorenal side effects, the anti-oxidant properties of taurine emerge through reduction of GSH, LPO, NO formation and upregulation of anti-oxidant enzymes (223).

Apart from its significant anti-oxidant and anti-inflammatory role, taurine exerts a great effect on cholesterol levels. In particular, taurine has been documented to be a direct liver $\mathrm{X}$ receptor $\alpha$ (LXR- $\alpha$ ) ligand, which modulates the expression of genes implicated in reverse cholesterol transport in macrophages, this way compromising cholesterol to lipid accumulation without increasing hepatic fatty acid synthesis (224). Paradoxically, increased nuclear translocation of sterol regulatory element-binding protein-1c (SREBP-1c) results in lipogenesis in the liver, through induction of LXR- $\alpha$ (225). In this direction, low-dose taurine administration $(0.1 \mathrm{~g} / \mathrm{kg}$ body weight/day for 5 weeks) has also been shown to restore structural changes in the liver of an MSG-induced obesity model (226). Consistent with the above, it has been reported that taurine negatively affects the serum cholesterol levels of rats on a high cholesterol diet (134). From a clinical point of view, taurine has been suggested as a potential effective therapeutic agent for hyperlipidemia and calcium deficiency-related metabolic disorders. Indeed, taurine has been shown to lower triglyceride and cholesterol levels in healthy young human adults in a dose of 6 grammars of taurine per day for 21 days, following a high fat and cholesterol diet (227). On a similar note, it has been reported that administration of 3 grammars of taurine per day for 42 days reduces plasma triglyceride and total cholesterol to normal levels in overweight human subjects (228).

The beneficial effect of taurine on hepatic side-effects. In addition, the beneficial effect of taurine against toxin-mediated hepatic damage has been substantiated by several examples. According to Miyazaki et al, taurine can reverse carbon tetrachloride $\left(\mathrm{CCL}_{4}\right)$-induced hepatic damage; histologically, fibrotic infiltrations of both pericentral and periportal regions are restored following treatment with taurine, as shown by immunohistochemical stainings (229). In parallel, it has been shown that a combination of taurine and hesperidin can afford benefit to $\mathrm{CCL}_{4}$-administered rats from acute kidney and testicular damage (230). The antithrombotic effect of taurine has been proved very significant in patients with acute kidney damage, who have increased risk for atherothrombotic and cardioembolic danger $(231,232)$. Recently, the European Dialysis Working Group has presented convincing evidence about the benefits of antiplatelet and anticoagulant drugs, recommending their use in patients with chronic kidney disease requiring dialysis (231). In another case, 
acetaminophen (N-acetyl-p-aminophenol, APAP) was shown to induce hepatic failure, causing significant alterations in hepatic metabolism (233); it was observed that, following the entry of APAP in hepatocytes, the greatest proportion of APAP (90\%) is converted to innocuous molecules, and only a small fraction of APAP (5-10\%) yields the toxic electrophile $\mathrm{N}$-acetyl-para-benzoquinoimine (NAPQI), due to the activity of cytochrome P450 isoforms, mainly CYP 2E1, CYP 1A2, CYP 3A2 (234). Specifically, all the APAP-mediated changes are mediated by the binding of NAPQI to mitochondrial proteins of the respiratory chain, thus attenuating ATP formation and culminating in excessive $\mathrm{O}_{2}^{-}$formation (235). Several mechanisms have been suggested to account for the liver damage caused by APAP, including disturbed hepatic GSH reserves, inhibition of cytochrome P450 enzyme activity, elevation of intracellular calcium levels, increased LPO and ROS formation (236). In addition to depleting intrahepatic GSH, APAP seems to decrease the activity of anti-oxidant enzymes (SOD, CAT, GPx), as well as of enzymes involved in glutathione redox cycling (glutathione reductase, GR), utilization (glutathione S-transferase, GST) and synthesis (gamma-glutamylcysteine synthetase) (237). In this context, taurine has been shown to improve the effects of APAP on both oxidative stress and glutathione redox metabolism (238). Taurine administered at a dose of $2.4 \mathrm{mmol} / \mathrm{kg}$ for $30 \mathrm{~min}$ following administration of $800 \mathrm{mg} / \mathrm{kg}$ APAP appeared to successfully alleviate both DNA damage signals and oxidative indices (238). This was achieved by i) reducing MDA formation, ii) regulating glutathione cycling-utilization-synthesis cycle, iii) increasing the already reduced glutathione to glutathione disulfide (GSH/GSSG) ratio and iv) increasing the activity of all anti-oxidant enzymes (238). Notably, hepatic damage mediated by paracetamol intake can be monitored through plasma and urine taurine levels (239). In addition to the above, taurine has been reported to alleviate hepatic damage caused by hexavalent chromium and tamoxifen in mice $(240,241)$, as well as lead, cadmium and copper in rats (242-244). In the case of thioacetamide (TAA)-induced liver damage, taurine supplementation has been proved to be advantageous due to its ROS-scavenging capacity and its potential to normalize mitochondrial energy expenditure via suppressing mitochondrial swelling (245). Taurine administration at doses of $400 \mathrm{mg} / \mathrm{kg}$, intraperitoneally (every $12 \mathrm{~h}$ beginning at $24 \mathrm{~h}$ prior to the first TAA injection) has been reported to reduce serum transaminase activity and hepatic LPO, possibly due to its scavenging properties (245). In addition, taurine supplementation has been shown to regulate glutathione metabolizing enzymes without affecting the activity of hepatic anti-oxidant enzymes in TAA-treated rats (246).

On a similar note, epidemiological studies have demonstrated that chronic oxidearsenous trioxide $\left(\mathrm{As}_{2} \mathrm{O}_{3}\right)$ hepatic insult can lead to liver injury, which may present as fibrosis or cirrhosis or even cancer (247). Four years ago, Li et al found that exposure to $\mathrm{As}_{2} \mathrm{O}_{3}$ causes extensive hepatic injury, as hepatocytes convert oxidearsenous trioxide to dimethyl arsenic acid and monomethyl arsenic acid (248). Liver injury is manifested via increased expression levels of alkaline phosphatase (ALP) and alanine aminotransferase (ALT) in serum, which represent reliable markers of liver damage (248). In this context, taurine appears to attenuate $\mathrm{As}_{2} \mathrm{O}_{3}$ mediated toxicity (249), possibly by reducing the expression levels of phosphorylated JNK kinases, thereby ruling out the possibility that hepatic cells follow the apoptotic route after taurine treatment in $\mathrm{As}_{2} \mathrm{O}_{3}$-administered rats (248). In the meantime, the $\mathrm{As}_{2} \mathrm{O}_{3}$-induced toxicity has been differentially documented in terms of autophagy. While older studies have suggested that low $\mathrm{As}_{2} \mathrm{O}_{3}$ supplementation suppresses autophagy (250), more recent data have demonstrated the induction of autophagic cell death in INS-1 cells or HepG2 cells following $\mathrm{NaAsO}_{2}$ or $\mathrm{As}_{2} \mathrm{O}_{3}$ treatment (251). In this frame, Qiu et al highlighted the contribution of arsenic exposure to nonalcoholic steatohepatitis (NASH): Arsenic trioxide $\left(\mathrm{As}_{2} \mathrm{O}_{3}\right)$ treatment was shown to activate NASH in mice via the induction of autophagy and NLRP3 inflammasome activation, ultimately leading to dysregulation of lipid-related genes and to lipid accumulation. Interestingly, taurine supplementation appeared to reverse $\mathrm{As}_{2} \mathrm{O}_{3}$-mediated liver inflammation by inhibiting the autophagic-CTSB-NLRP3 inflammasomal pathway rather than decreasing lipid accumulation (252). Furthermore, taurine can suppress autophagy and oxidative burst by inducing the expression of the nuclear hormone receptor such as peroxisome proliferator-activated receptor gamma (PPAR- $\gamma$ ) in both HepG2 cells and liver tissues of animal models (251).

Interestingly, taurine's activity can be amplified when used in combination with other anti-oxidant drugs. For example, when taurine is combined with dimercaptosuccinate, it appears to significantly enhance the activity of anti-oxidant enzymes in the liver (253). Elsewhere, taurine has been shown to alleviate liver injury caused by carbon tetrachloride $\left(\mathrm{CCL}_{4}\right)$ and to reverse the characteristic symptoms of liver fibrosis such as portal inflammation, severe centrilobular necrosis, and excessive deposition of collagen (254). Taurine counteracts $\mathrm{CCL}_{4}$-mediated damage by maintaining energy homeostasis, preventing ROS accumulation, and enhancing the interaction of Thioredoxin 1 (Txn1) with numerous proteins involved in glycolysis (254). In diethyl nitrosamine (DEN)-mediated liver injury, a combination treatment scheme consisting of curcumin and taurine displayed strong anti-inflammatory properties, by reducing the expression levels of IL-2 and IFN- $\gamma$, thereby preventing mitochondrial disturbance in malignant cells (255). Besides, the viability of cultured human hepatoma cells was significantly decreased when taurine was administered in combination with curcumin, as opposed to those two compounds administered separately (256). Furthermore, a combination treatment scheme consisting of tea polyphenols (TPs) and taurine has been shown to decrease oxidative damage markers (alanine transaminase and aspartate transaminase) and lipid destruction (257). In the case of hepatic damage induced by chronic ethanol administration (258) or methotrexate (anti-leukemic drug) (259), taurine's therapeutic action appears to rely on decreasing the MDA content and restoring GSH levels. Accordingly, the carnosine and taurine combined treatment scheme appeared to protect the livers of animal models from D galactose (GAL) mediated liver damage through a significant reduction of MDA and of PC content and through a slight upregulation of anti-oxidant enzymes, including SOD and GPx (260). It has therefore been proposed that taurine rescues injured hepatocytes from various toxins due to its cytoprotective role as an intracellular calcium flux regulator, an anti-oxidant, and an osmoregulator. 
Last but not least, metabolomic data analysis has highlighted a diagnostic importance for taurine in the detection of hyperlactatemia following alcohol consumption (261). Increased quantities of N-acetyltaurine (NAT), which uses taurine as the main substrate for its synthesis, have been observed in the urine samples of Cyp2e1-null mice following ethanol consumption (261). Accordingly, taurine levels are significantly reduced in certain liver disorders and xenobiotic-mediated liver damage and are therefore used for the clinical detection of hepatic injury in plasma and urine samples $(262,263)$.

\section{The anti-oxidant properties of taurine in various toxic-mediated insults}

The cytoprotective role of taurine has been substantiated in various toxin-mediated oxidative stress conditions. For example, taurine has been demonstrated to inhibit oxidative stress-induced lung damage (264), whereas more recently taurine supplementation has been shown to increase the activity of anti-oxidant enzymes in the lungs (265). In other cases, taurine has shown to exert anti-oxidant activity against bleomycin-induced lung injury (266) or against amiodarone (267) or paraquat $(268,269)$ or sumatriptan mediated lipid peroxidation (LPO), and mitochondrial injury (270). Other studies have indicated that oral supplementation of taurine probably serves as a protective agent against damage mediated by nitrogen dioxide $\left(\mathrm{NO}_{2}\right)$ (271). Interestingly, the treatment of MRC-5 fibroblasts with $20 \mathrm{mM}$ of taurine has appeared to inhibit the lipopolysaccharide (LPS)-induced ROS formation and the activation of the MAPK signaling pathway (272). Similarly, taurine seems to confer protection against testicular toxicity. For example, taurine has been found to counteract the effects of sodium arsenite $\left(\mathrm{NaAsO}_{2}\right)$-mediated oxidative insults to the testes (273). It seems that taurine serves as an anti-oxidant and as an anti-apoptotic agent by inhibiting the activation of two members of the MAPK family, ERK1/2 and p38 MAPK (273). Probably, in this way, taurine protects the testes from damage caused by sodium arsenite exposure, through inhibition of lipid peroxidation. In another study, taurine has been shown to alleviate the arsenic- associated adverse effects in the testes by functioning as a capacitating agent or as a sperm motility factor (274). In the same context, taurine appears to be remarkably useful against endosulfan-mediated adverse effects. In an experimental rat model using endosulfan to cause testicular toxicity, endosulfan has appeared to induce oxidative stress and apoptosis, as demonstrated by increased $\mathrm{H}_{2} \mathrm{O}_{2}$ levels, lipid accumulation and reduced activity of anti-oxidant enzymes (SOD, CAT, GPx), as well as altered reduced GSH content and mitochondrial cytochrome c release (275). In addition to providing complementary insights into the mode of action of endosulfan-induced toxicity, taurine has been shown to reverse all of the endosulfan-induced effects, by acting as a protective agent against testicular toxicity in rats (275). In another case, taurine emerges as an effective cytoprotective agent against cisplatin-mediated testicular apoptosis, due to its anti-oxidant nature (276). Indeed, taurine ameliorates testicular damage in rats, through upregulation of anti-oxidant enzymes (276). Finally, the protective properties of taurine have been confirmed in murine testicular Leydig TM3 cells, preventing oxidative stress through activation of autophagy (277). Last but not least, the combination of curcumin and taurine exerts beneficial effect on Bisphenol A (BPA)-mediated testicular dysfunction in rats, though its inhibitory action on MDA levels and its possibility to upregulate anti-oxidant enzymes (278).

\section{Conclusions}

Taurine is a cytoprotective molecule, which is implicated in a wide spectrum of processes such as energy production, neuromodulation, calcium homeostasis and osmoregulation, all of which support its anti-oxidant nature. To our knowledge, this is the first study that discusses the anti-oxidant nature of taurine and its underlying molecular mechansims of action in various pathological circumstances related to oxidative stress. Indeed, taurine emerges as a promising therapeutic approach against CNS-related disorders, as well as defects in the cardiovascular system, and defects in the skeletal muscle and metabolism. Leveraging next-generation sequencing, the multilayered characterization of taurine therapeutic targets will give comprehensive insights into the potential clinical use of taurine.

However, an important limitation of this review article is the paucity of clinical studies to examine taurine's therapeutic efficacy. The pharmacodynamic and pharmacokinetic properties of taurine are requested to elucidate taurine's effectiveness in a clinical setting, allowing the correct design of clinical trials. In this way, we will acquire information about taurine's duration and dose administration in patients bearing various oxidative stress-related diseases. Indeed, clinical trials will confirm the benefits of taurine's action in patients undergoing oxidative stress in a safe manner.

\section{Acknowledgements}

Not applicable.

\section{Funding}

The present study was supported by The State Scholarships Foundation (I.K.Y; grant no. 2018-050-0502-13155). This work was also supported by the European Infrastructure For Translational Medicine-Greece project (grant no. MIS 5028091) which is implemented under the Action 'Reinforcement of the Research and Innovation Infrastructure', funded by the Operational Program 'Competitiveness, Entrepreneurship and Innovation' (grant no. NSRF 2014-2020) and co-financed by Greece and the European Union (European Regional Development Fund).

\section{Availability of data and materials}

Not applicable.

\section{Authors' contributions}

SB, MA, DAS, PI, VZ, AP, MIP, IC and AMK were involved in the conception and design of the study. SB performed the literature search, designed the figure, interpreted the data and wrote the manuscript. SB, MA, PI and VZ contributed 
to editing the manuscript. SB, MA, DAS, PI, VZ, AP, MIP, IC and AMK contributed to the acquisition of data. SB and PI contributed to the analysis and interpretation of data. All authors have read and approved the final manuscript. Data sharing is not applicable.

\section{Ethics approval and consent to participate}

Not applicable.

\section{Patient consent for publication}

Not applicable.

\section{Competing interests}

DAS is the Editor-in-Chief for the journal, but had no personal involvement in the reviewing process, or any influence in terms of adjudicating on the final decision for this article. The other authors declare that they have no competing interests.

\section{References}

1. Tiedemann F and Gmelin L: Einige neue bestandtheile der galle des ochsen. Ann Phys 85: 326-337, 1827.

2. Kim SJ, Lee HW and Gupta RC: Taurine, Bone growth and bone development. Curr Nutr Food Sci 4: 135-144, 2008.

3. Hayes KC, Carey RE and Schmidt SY: Retinal degeneration associated with taurine deficiency in the cat. Science 188: 949-951, 1975.

4. Aerts L and Van Assche FA: Taurine and taurine-deficiency in the perinatal period. J Perinat Med 30: 281-286, 2002

5. Chesney RW: Taurine: Its biological role and clinical implications. Adv Pediatr 32: 1-42, 1985.

6. Lee JY, Jung DW, Park HA, Kim SJ, Chung JH, Moon CK and Kim YC: Effect of taurine on biliary excretion and metabolism of acetaminophen in male hamsters. Biol Pharm Bull 27: 1792-1796, 2004

7. Liu QR, López-Corcuera B, Nelson H, Mandiyan S and Nelson N: Cloning and expression of a cDNA encoding the transporter of taurine and beta-alanine in mouse brain. Proc Natl Acad Sci USA 89: 12145-12149, 1992.

8. Chesney RW, Lippincott S, Gusowski N, Padilla M and Zelikovic I: Studies on renal adaptation to altered dietary amino acid intake: Tissue taurine responses in nursing and adult rats. J Nutr 116: 1965-1976, 1986

9. Räihä NC, Heinonen K, Rassin DK and Gaull GE: Milk protein quantity and quality in low-birthweight infants: I. Metabolic responses and effects on growth. Pediatrics 57: 659-684, 1976.

10. Park E, Park SY, Wang C, Xu J, LaFauci G and Schuller-Levis G: Cloning of murine cysteine sulfinic acid decarboxylase and its mRNA expression in murine tissues. Biochim Biophys Acta 1574: 403-406, 2002.

11. Bella DL, Kwon YH, Hirschberger LL and Stipanuk MH: Post-transcriptional regulation of cysteine dioxygenase in rat liver. Adv Exp Med Biol 483: 71-85, 2000.

12. Redmond HP, Stapleton PP, Neary P and Bouchier-Hayes D: Immunonutrition: The role of taurine. Nutrition 14: 599-604, 1998

13. Wójcik OP, Koenig KL, Zeleniuch-Jacquotte A, Costa M and Chen Y: The potential protective effects of taurine on coronary heart disease. Atherosclerosis 208: 19-25, 2010.

14. Hansen SH: The role of taurine in diabetes and the development of diabetic complications. Diabetes Metab Res Rev 17: 330-346, 2001.

15. Chesney RW, Han $X$ and Patters AB: Taurine and the renal system. J Biomed Sci 17 (Suppl 1): S4, 2010.

16. Huxtable RJ: Physiological actions of taurine. Physiol Rev 72 101-163, 1992

17. Sarsour EH, Kumar MG, Chaudhuri L, Kalen AL and Goswami PC: Redox control of the cell cycle in health and disease. Antioxid Redox Signal 11: 2985-3011, 2009.

18. Chiang JY: Bile acid metabolism and signaling. Compr Physiol 3: 1191-212, 2013.
19. Goodman CA, Horvath D, Stathis C, Mori T, Croft K, Murphy RM and Hayes A: Taurine supplementation increases skeletal muscle force production and protects muscle function during and after high-frequency in vitro stimulation. J Appl Physiol (1985) 107: 144-154, 2009.

20. Sturman JA and Chesney RW: Taurine in pediatric nutrition Pediatr Clin North Am 42: 879-897, 1995.

21. Lien YH, Shapiro JI and Chan L: Effects of hypernatremia on organic brain osmoles. J Clin Invest 85: 1427-1435, 1990.

22. Lang F, Madlung J, Uhlemann AC, Risler T and Gulbins E: Cellular taurine release triggered by stimulation of the Fas(CD95) receptor in Jurkat lymphocytes. Pflugers Arch 436: 377-383, 1998.

23. Schaffer S, Takahashi K and Azuma J: Role of osmoregulation in the actions of taurine. Amino Acids 19: 527-546, 2000.

24. Yancey PH: Organic osmolytes as compatible, metabolic and counteracting cytoprotectants in high osmolarity and other stresses. J Exp Biol 208: 2819-2830, 2005.

25. Howard M, Fischer H, Roux J, Santos BC, Gullans SR, Yancey PH and Welch WJ: Mammalian osmolytes and S-nitrosoglutathione promote delta F508 cystic fibrosis transmembrane conductance regulator (CFTR) protein maturation and function. J Biol Chem 278: 35159-35167, 2003.

26. Marcinkiewicz J, Kontny E: Taurine and inflammatory diseases. Amino Acids 46: 7-20, 2014.

27. Sukhotnik I, Aranovich I, Ben Shahar Y, Bitterman N, Pollak Y, Berkowitz D, Chepurov D, Coran AG and Bitterman A: Effect of taurine on intestinal recovery following intestinal ischemia-reperfusion injury in a rat. Pediatr Surg Int 32: 161-168, 2016.

28. Gharibani P, Modi J, Menzie J, Alexandrescu A, Ma Z, Tao R, Prentice $\mathrm{H}$ and $\mathrm{Wu} J \mathrm{Y}$ : Comparison between single and combined post-treatment with S-Methyl-N,N-diethylthiolcarbamate sulfoxide and taurine following transient focal cerebral ischemia in rat brain. Neuroscience 300: 460-473, 2015

29. Yang Y, Zhang Y, Liu X, Zuo J, Wang K, Liu W and Ge J: Exogenous taurine attenuates mitochondrial oxidative stress and endoplasmic reticulum stress in rat cardiomyocytes. Acta Biochim Biophys Sin (Shanghai) 45: 359-367, 2013.

30. Wang Z, Ohata Y, Watanabe Y, Yuan Y, Yoshii Y, Kondo Y, Nishizono $S$ and Chiba T: Taurine improves lipid metabolism and increases resistance to oxidative stress. J Nutr Sci Vitaminol (Tokyo) 66: 347-356, 2020.

31. Nagai K, Fukuno S, Oda A and Konishi H: Protective effects of taurine on doxorubicin-induced acute hepatotoxicity through suppression of oxidative stress and apoptotic responses. Anticancer Drugs 27: 17-23, 2016.

32. Chang CY, Shen CY, Kang CK, Sher YP, Sheu WH, Chang CC and Lee TH: Taurine protects HK-2 cells from oxidized LDL-induced cytotoxicity via the ROS-mediated mitochondrial and p53-related apoptotic pathways. Toxicol Appl Pharmacol 279: 351-363, 2014.

33. Prideaux M, Kitase Y, Kimble M, O'Connell TM and Bonewald LF: Taurine, an osteocyte metabolite, protects against oxidative stress-induced cell death and decreases inhibitors of the Wnt/ $\beta$-catenin signaling pathway. Bone 137: 115374, 2020.

34. Lou J, Han D, Yu H, Yu G, Jin M and Kim SJ: Cytoprotective effect of taurine against hydrogen peroxide-induced oxidative stress in UMR-106 cells through the Wnt/ $\beta$-catenin signaling pathway. Biomol Ther (Seoul) 26: 584-590, 2018.

35. Suzuki T, Suzuki T, Wada T, Saigo K and Watanabe K: Taurine as a constituent of mitochondrial tRNAs: New insights into the functions of taurine and human mitochondrial diseases. EMBO J 21: 6581-6589, 2002.

36. Schaffer SW, Jong CJ, Ito T and Azuma J: Role of taurine in the pathologies of MELAS and MERRF. Amino Acids 46: 47-56, 2014

37. Homma K, Toda E, Osada H, Nagai N, Era T, Tsubota K, Okano $\mathrm{H}$ and Ozawa Y: Taurine rescues mitochondria-related metabolic impairments in the patient-derived induced pluripotent stem cells and epithelial-mesenchymal transition in the retinal pigment epithelium. Redox Biol 41: 101921, 2021.

38. Sturman JA: Taurine in development. Physiol Rev 73: 119-147, 1993.

39. Lima L, Obregón F, Urbina M, Carreira I, Baccichet E and Peña S: Taurine concentration in human blood peripheral lymphocytes. In: Taurine 5. Advances in Experimental Medicine and Biology. Lombardini JB, Schaffer SW and Azuma J (eds). Vol 526, Springer, Boston, MA, pp297-304, 2013.

40. Iruloh CG, D'Souza SW, Speake PF, Crocker I, Fergusson W, Baker PN, Sibley CP and Glazier JD: Taurine transporter in fetal T lymphocytes and platelets: Differential expression and functional activity. Am J Physiol Cell Physiol 292: C332-C341, 2007. 
41. OjaSS and Saransaari P(eds): Taurine 6. Advances in Experimental Medicine and Biology. Vol 583. Springer, New York, NY, p556, 2006.

42. Lubec B, Ya-hua Z, Pertti S, Pentti T, Kitzmüller E and Lubec G: Distribution and disappearance of the radiolabeled carbon derived from L-arginine and taurine in the mouse. Life Sci 60: 2373-2381, 1997.

43. Menzie J, Pan C, Prentice $\mathrm{H}$ and Wu JY: Taurine and central nervous system disorders. Amino Acids 46: 31-46, 2014.

44. Schaffer SW, Jong CJ, Ramila KC and Azuma J: Physiological roles of taurine in heart and muscle. J Biomed Sci 17 (Suppl 1): S2, 2010 .

45. Schaffer SW, Shimada-Takaura K, Jong CJ,Ito T and Takahashi K: Impaired energy metabolism of the taurine-deficient heart Amino Acids 48: 549-558, 2016.

46. Jong CJ, Azuma J and Schaffer S: Mechanism underlying the antioxidant activity of taurine: Prevention of mitochondrial oxidant production. Amino Acids 42: 2223-2232, 2012

47. Jong C, Ito T, Mozaffari M, Azuma J and Schaffer S: Effect of beta-alanine treatment on mitochondrial taurine level and 5-taurinomethyluridine content. J Biomed Sci 17 (Suppl 1): S25, 2010.

48. Vafai SB and Mootha VK: Mitochondrial disorders as windows into an ancient organelle. Nature 491: 374-833, 2012.

49. Jansen M, Ten Klooster JP, Offerhaus GJ, Clevers H: LKB1 and AMPK family signaling: The intimate link between cell polarity and energy metabolism. Physiol 89: 777-798, 2009.

50. Jong CJ, Azuma J and Schaffer SW: Role of mitochondrial permeability transition in taurine deficiency-induced apoptosis. Exp Clin Cardiol 16: 125-128, 2011.

51. Ricci C, Pastukh V, Leonard J, Turrens J, Wilson G, Schaffer D and Schaffer SW: Mitochondrial DNA damage triggers mitochondrial-superoxide generation and apoptosis. Am J Physiol Cell Physiol 294: C413-C422, 2008.

52. Shetewy A, Shimada-Takaura K, Warner D, Jong CJ, Mehdi AB Alexeyev M, Takahashi K and Schaffer SW: Mitochondrial defects associated with $\beta$-alanine toxicity: Relevance to hyper-beta-alaninemia. Mol Cell Biochem 416: 11-22, 2016.

53. Schuller-Levis G and Park E: Is taurine a biomarker? Adv Clin Chem 41: 1-21, 2006.

54. Cozzi R, Ricordy R, Bartolini F, Ramadori L, Perticone P and De Salvia R: Taurine and ellagic acid: Two differently-acting natural antioxidants. Environ Mol Mutagen 26: 248-254, 1995.

55. Aruoma OI, Halliwell B, Hoey BM and Butler J: The antioxidant action of taurine, hypotaurine and their metabolic precursors. Biochem J 256: 251-255, 1988.

56. Timbrell JA, Seabra V and Waterfield CJ: The in vivo and in vitro protective properties of taurine. Gen Pharmacol 26: 453-462, 1995.

57. Chen WQ, Jin H, Nguyen M, Carr J, Lee YJ, Hsu CC, Faiman MD, Schloss JV and Wu JY: Role of taurine in regulation of intracellular calcium level and neuroprotective function in cultured neurons. J Neurosci Res 66: 612-619, 2001.

58. Yamauchi-Takihara K, Azuma J, Kishimoto S, Onishi S and Sperelakis N: Taurine prevention of calcium paradox-related damage in cardiac muscle. Its regulatory action on intracellular cation contents. Biochem Pharmacol 37: 2651-2658, 1988.

59. Parvez S, Tabassum H, Banerjee BD and Raisuddin S: Taurine prevents tamoxifen-induced mitochondrial oxidative damage in mice. Basic Clin Pharmacol Toxicol 102: 382-387, 2008.

60. Sener G, Ozer Sehirli A, Ipçi Y, Cetinel S, Cikler E, Gedik N and Alican I: Taurine treatment protects against chronic nicotine-induced oxidative changes. Fundam Clin Pharmacol 155-164, 2005 .

61. Şener G,Şehirli Ö,İpçi Y,Çetinel Ş,ÇiklerE, Gedik N and Alican I Protective effects of taurine against nicotine-induced oxidative damage of rat urinary bladder and kidney. Pharmacology 74 37-44, 2005

62. Jafri AJA, Agarwal R, Iezhitsa I, Agarwal P and Ismail NM: Taurine protects against NMDA-induced retinal damage by reducing retinal oxidative stress. Amino Acids 51: 641-646, 2019.

63. Gordon RE, Heller RF and Heller RF: Taurine protection of lungs in hamster models of oxidant injury: A morphologic time study of paraquat and bleomycin treatment. In: Taurine. Advances in Experimental Medicine and Biology. Lombardini JB Schaffer SW and Azuma J (eds). Vol 315. Springer, Boston, MA, pp319-328, 1992.

64. Kim C and Cha YN: Taurine chloramine produced from taurine under inflammation provides anti-inflammatory and cytoprotective effects. Amino Acids 46: 89-100, 2014
65. Hsieh TJ, Zhang SL, Filep JG, Tang SS, Ingelfinger JR and Chan JS: High glucose stimulates angiotensinogen gene expression via reactive oxygen species generation in rat kidney proximal tubular cells. Endocrinology 143: 2975-2985, 2002.

66. Kettle AJ, van Dalen CJ and Winterbourn CC: Peroxynitrite and myeloperoxidase leave the same footprint in protein nitration. Redox Rep 3: 257-258, 1997.

67. Schaffer S, Solodushko V, Pastukh V, Ricci C and Azuma J: Possible cause of taurine-deficient cardiomyopathy: Potentiation of angiotensin II action. J Cardiovasc Pharmacol 41: 751-759, 2003.

68. Vohra BP and Hui X: Taurine protects against carbon tetrachloride toxicity in the cultured neurons and in vivo. Arch Physiol Biochem 109: 90-94, 2001.

69. Nonaka H, Tsujino T, Watari Y, Emoto N and Yokoyama M: Taurine prevents the decrease in expression and secretion of extracellular superoxide dismutase induced by homocysteine: Amelioration of homocysteine-induced endoplasmic reticulum stress by taurine. Circulation 104: 1165-1170, 2001.

70. Anand P, Rajakumar D, Jeraud M, Felix AJ and Balasubram T: Effects of taurine on glutathione peroxidase, glutathione reductase and reduced glutathione levels in rats. Pak J Biol Sci 14: 219-225, 2011.

71. Oudit GY, Trivieri MG, Khaper N, Husain T, Wilson GJ, Liu P, Sole MJ and Backx PH: Taurine supplementation reduces oxidative stress and improves cardiovascular function in an iron-overload murine model. Circulation 109: 1877-1885, 2004.

72. Das J and Sil PC: Taurine ameliorates alloxan-induced diabetic renal injury, oxidative stress-related signaling pathways and apoptosis in rats. Amino Acids 43: 1509-1523, 2012.

73. Sayed RH, Salem HA and El-Sayeh BM: Potential protective effect of taurine against dibromoacetonitrile-induced neurotoxicity in rats. Environ Toxicol Pharmacol 34: 849-857, 2012.

74. Das J, Ghosh J, Manna P and Sil PC: Taurine protects rat testes against doxorubicin-induced oxidative stress as well as p53, Fas and caspase 12-mediated apoptosis. Amino Acids 42: 1839-1855, 2012.

75. Bhavsar TM, Cantor JO, Patel SN and Lau-Cam CA: Attenuating effect of taurine on lipopolysaccharide-induced acute lung injury in hamsters. Pharmacol Res 60: 418-428, 2009.

76. Ito T, Schaffer SW and Azuma J: The potential usefulness of taurine on diabetes mellitus and its complications. Amino Acids 42: 1529-1539, 2012.

77. Rikimaru M, Ohsawa Y, Wolf AM, Nishimaki K, Ichimiya H, Kamimura N, Nishimatsu S, Ohta S and Sunada Y: Taurine ameliorates impaired the mitochondrial function and prevents stroke-like episodes in patients with MELAS. Intern Med 51: 3351-3357, 2012.

78. Hagar HH, El Etter E and Arafa M: Taurine attenuates hypertension and renal dysfunction induced by cyclosporine a in rats. Clin Exp Pharmacol Physiol 33: 189-196, 2006.

79. Shao X, Hu Z, Hu C, Bu Q, Yan G, Deng P, Lv L, Wu D, Deng Y, Zhao J,et al: Taurine protects methamphetamine-induced developmental angiogenesis defect through antioxidant mechanism. Toxicol Appl Pharmacol 260: 260-270, 2012.

80. Brosnan JT and Brosnan ME: The sulfur-containing amino acids: An overview. J Nutr 136 (Suppl 6): 1636S-1640S, 2006.

81. Wenting L, Ping L, Haitao J, Meng Q and Xiaofei R: Therapeutic effect of taurine against aluminum-induced impairment on learning, memory and brain neurotransmitters in rats. Neurol 35: $1579-1584,2014$.

82. Albrecht J and Schousboe A: Taurine interaction with neurotransmitter receptors in the CNS: An update. Neurochem Res 30: 1615-1621, 2005.

83. Wu H, Jin Y, Wei J, Jin H, Sha D and Wu JY: Mode of action of taurine as a neuroprotector. Brain Res 1038: 123-131, 2005.

84. Chen C, Xia S, He J, Lu G, Xie Z and Han H: Roles of taurine in cognitive function of physiology, pathologies and toxication. Life Sci 231: 116584, 2019.

85. Ochoa-de la Paz L, Zenteno E, Gulias-Cañizo R and Quiroz-Mercado H: Taurine and GABA neurotransmitter receptors, a relationship with therapeutic potential? Expert Rev Neurother 19: 289-291,2019.

86. Zhou J, Li Y, Yan G, Bu Q, Lv L, Yang Y, Zhao J, Shao X, Deng Y, Zhu R, et al: Protective role of taurine against morphine-induced neurotoxicity in C6 cells via inhibition of oxidative stress. Neurotox Res 20: 334-342, 2011.

87. Bulley S and Shen W: Reciprocal regulation between taurine and glutamate response via $\mathrm{Ca}^{2+}$-dependent pathways in retinal third-order neurons. J Biomed Sci 17 (Suppl 1): S5, 2010.

88. Makarova LM, Pogorely̌ VE, Voronkov AV and Novikova NA: Modern notions about the role of taurine in the central nervous system. Eksp Klin Farmakol 77: 38-44, 2014 (In Russian). 
89. Wu JY and Prentice H: Role of taurine in the central nervous system. J Biomed Sci 17 (Suppl 1): S1, 2010.

90.Zhang C, Liu F, Liu X and Chen D: Protective effect of $\mathrm{N}$-acetylcysteine against BDE-209-induced neurotoxicity in primary cultured neonatal rat hippocampal neurons in vitro. Int J Dev Neurosci 28: 521-528, 2010.

91. Abramov AY and Duchen MR: Mechanisms underlying the loss of mitochondrial membrane potential in glutamate excitotoxicity. Biochim Biophys Acta 1777: 953-964, 2008

92.Prentice H, Modi JP and Wu JY: Mechanisms of neuronal protection against excitotoxicity, endoplasmic reticulum stress, and mitochondrial dysfunction in stroke and neurodegenerative diseases. Oxid Med Cell Longev 2015: 964518, 2015.

93. McCullough KD, Martindale JL, Klotz LO, Aw TY and Holbrook NJ: Gadd153 sensitizes cells to endoplasmic reticulum stress by down-regulating $\mathrm{Bcl} 2$ and perturbing the cellular redox state. Mol Cell Biol 21: 1249-1259, 2001.

94. Urano F, Wang X, Bertolotti A, Zhang Y, Chung P, Harding HP and Ron D: Coupling of stress in the ER to activation of JNK protein kinases by transmembrane protein kinase IRE1. Science 287: 664-666, 2000.

95.Zhang R, Jiang M, Zhang J, Qiu Y, Li D, Li S, Liu J, Liu C, Fang $\mathrm{Z}$ and Cao F: Regulation of the cerebrovascular smooth muscle cell phenotype by mitochondrial oxidative injury and endoplasmic reticulum stress in simulated microgravity rats via the PERK-eIF2 $\alpha$-ATF4-CHOP pathway. Biochim Biophys Acta Mol Basis Dis 1866: 165799, 2020.

96. Aslan Karakelle N, Dinçer S and Yar Sağlam AS: The effect of intracerebroventricular amyloid beta 1-42 application on cognitive functions in aged rats supplemented with taurine and the change of peroxisomal proteins in this process. Brain Res Bull 172: 89-97, 2021.

97. Lee DS and Cheong SH: Taurine have neuroprotective activity against oxidative damage-induced HT22 Cell death through heme oxygenase-1 pathway. In: Taurine 10. Advances in Experimental Medicine and Biology. Lee DH, Schaffer SW, Park E and Kim HW (eds). Vol 975. Springer, Dordrecht, pp159-171, 2017.

98.Zhang X, Wang X, Zhang J, Pan X, Jiang J and Li Y: Effects of taurine on alterations of neurobehavior and neurodevelopment key proteins expression in infant rats by exposure to hexabromocyclododecane. In: Taurine 10. Advances in Experimenta Medicine and Biology. Lee DH, Schaffer SW, Park E, Kim HW (eds). Vol 975. Springer, Dordrecht, pp119-30, 2017.

99. Chen R, Liu S, Piao F, Wang Z, Qi Y, Li S, Zhang D and Shen J: 2,5-hexanedione induced apoptosis in mesenchymal stem cells from rat bone marrow via mitochondria-dependent caspase- 3 pathway. Ind Health 53: 222-235, 2015.

100. Liu S, Piao F, Sun X, Bai L, Peng Y, Zhong Y, Ma N and Sun W: Arsenic-induced inhibition of hippocampal neurogenesis and its reversibility. Neurotoxicology 33: 1033-1039, 2012.

101. Yorifuji T, Kato T, Ohta H, Bellinger DC, Matsuoka K and Grandjean P: Neurological and neuropsychological functions in adults with a history of developmental arsenic poisoning from contaminated milk powder. Neurotoxicol Teratol 53: 75-80, 2016.

102. Li K, Wang D, Zhou X, Shao J, Li Y, Liu X, Zhang C, Zuo E, Shi X, Piao F and Li S: Taurine protects against arsenic-induced apoptosis Via PI3K/Akt pathway in primary cortical neurons. In: Taurine 11. Advances in Experimental Medicine and Biology. Hu J, Piao F, Schaffer SW, El Idrissi A and Wu JY (eds). Vol 1155. Springer, Singapore, pp747-754, 2019.

103. Piao F, Zhang Y, Yang L, Zhang C, Shao J, Liu X, Li Y and Li S: Taurine attenuates As2O3-induced autophagy in cerebrum of mouse through Nrf2 pathway. Adv Exp Med Biol 975: 863-870, 2017.

104. Cholanians AB, Phan AV, Ditzel EJ, Camenisch TD, Lau SS and Monks TJ: From the cover: Arsenic induces accumulation of $\alpha$-synuclein: Implications for synucleinopathies and neurodegeneration. Toxicol Sci 153: 271-281, 2016.

105. Escudero-Lourdes C: Toxicity mechanisms of arsenic that are shared with neurodegenerative diseases and cognitive impairment: Role of oxidative stress and inflammatory responses Neurotoxicology 53: 223-235, 2016.

106. Lee J, Giordano S and Zhang J: Autophagy, mitochondria and oxidative stress: Cross-talk and redox signalling. Biochem J 441: 523-540, 2012

107. Zhu XX, Yao XF, Jiang LP, Geng CY, Zhong LF, Yang G, Zheng BL and Sun XC: Sodium arsenite induces ROS-dependent autophagic cell death in pancreatic $\beta$-cells. Food Chem Toxicol 70: 144-150, 2014
108. Li Y, Hu Z, Chen B, Bu Q, Lu W, Deng Y, Zhu R, Shao X, Hou J, Zhao J, et al: Taurine attenuates methamphetamine-induced autophagy and apoptosis in PC12 cells through mTOR signaling pathway. Toxicol Lett 215: 1-7, 2012.

109. Menzie J, Prentice H and Wu JY: Neuroprotective mechanisms of taurine against ischemic stroke. Brain Sci 3: 877-907, 2013.

110. Schaffer SW, Jong CJ, Ito T and Azuma J: Effect of taurine on ischemia-reperfusion injury. Amino Acids 46: 21-30, 2014.

111. Yamori Y, Liu L, Mori M, Sagara M, Murakami S, Nara Y and Mizushima S: Taurine as the nutritional factor for the longevity of the japanese revealed by a world-wide epidemiological survey. In: Taurine 7. Advances in Experimental Medicine and Biology. Azuma J, Schaffer SW and Ito T (eds). Vol 643. Springer, New York, NY, pp13-25, 2009.

112. Lotocki G, de Rivero Vaccari JP, Perez ER, Sanchez-Molano J, Furones-Alonso O, Bramlett HM and Dietrich WD: Alterations in blood-brain barrier permeability to large and small molecules and leukocyte accumulation after traumatic brain injury: Effects of post-traumatic hypothermia. J Neurotrauma 26: 1123-1134, 2009.

113. Sun Q, Hu H, Wang W, Jin H, Feng G and Jia N: Taurine attenuates amyloid $\beta$ 1-42-induced mitochondrial dysfunction by activating of SIRT1 in SK-N-SH cells. Biochem Biophys Res Commun 447: 485-489, 2014

114. Niu X, Zheng S, Liu H and Li S: Protective effects of taurine against inflammation, apoptosis, and oxidative stress in brain injury. Mol Med Rep 18: 4516-4522, 2018

115. Saransaari P and Oja SS: Enhanced taurine release in cultured cerebellar granule cells in cell-damaging conditions. Amino Acids 17: 323-334, 1999.

116. Ricci L, Valoti M, Sgaragli G and Frosini M: Protection by taurine of rat brain cortical slices against oxygen glucose deprivation- and reoxygenation-induced damage. Eur J Pharmacol 621: 26-32, 2009

117. Abramov AY, Scorziello A and Duchen MR: Three distinct mechanisms generate oxygen free radicals in neurons and contribute to cell death during anoxia and reoxygenation. J Neurosci 27: $1129-1138,2007$

118. Han Z, Gao LY, Lin YH, Chang L, Wu HY, Luo CX and Zhu DY: Neuroprotection of taurine against reactive oxygen species is associated with inhibiting NADPH oxidases. Eur J Pharmacol 777: 129-135, 2016.

119. Pion PD, Kittleson MD, Rogers QR and Morris JG: Myocardial failure in cats associated with low plasma taurine: A reversible cardiomyopathy. Science 237: 764-768, 1987.

120. Moise NS, Pacioretty LM, Kallfelz FA, Stipanuk MH, King JM, Gilmour RF Jr: Dietary taurine deficiency and dilated cardiomyopathy in the fox. Am Heart J 121: 541-547, 1991.

121. Lake N: Loss of cardiac myofibrils: Mechanism of contractile deficits induced by taurine deficiency. Am J Physiol 264: H1323-H1326, 1993.

122. Ito T, Kimura Y, Uozumi Y, Takai M, Muraoka S, Matsuda T, Ueki K, Yoshiyama M, Ikawa M, Okabe M, et al: Taurine depletion caused by knocking out the taurine transporter gene leads to cardiomyopathy with cardiac atrophy. J Mol Cell Cardiol 44: 927-937, 2008

123. Ito T, Oishi S, Takai M, Kimura Y, Uozumi Y, Fujio Y, Schaffer SW and Azuma J: Cardiac and skeletal muscle abnormality in taurine transporter-knockout mice. J Biomed Sci 17 (Suppl 1): S20, 2010.

124. Huxtable R and Bressler R: Taurine concentrations in congestive heart failure. Science 184: 1187-1188, 1974

125. Jacobsen JG and Smith LH: Biochemistry and physiology of taurine and taurine derivatives. Physiol Rev 48: 424-511, 1968

126. Huxtable RJ and Sebring LA: Cardiovascular actions of taurine. Prog Clin Biol Res 125: 5-37, 1983.

127. Suwanich A, Wyss JM and Roysommuti S: Taurine supplementation in spontaneously hypertensive rats: Advantages and limitations for human applications. World J Cardiol 5: 404-409, 2013.

128. Bousquet P, Feldman J, Bloch R and Schwartz J: Central cardiovascular effects of taurine: Comparison with homotaurine and muscimol. J Pharmacol Exp Ther 219: 213-218, 1981.

129. Satoh H: Cardioprotective actions of taurine against intracellular and extracellular calcium-induced effects. In: Taurine in Health and Disease. Advances in Experimental Medicine and Biology. Huxtable RJ and Michalk D (eds). Vol 359, Springer, Boston, MA, pp181-196, 1994.

130. Qi B, Yamagami T, Naruse Y, Sokejima S and Kagamimori S: Effects of taurine on depletion of erythrocyte membrane Na-K ATPase activity due to ozone exposure or cholesterol enrichment. J Nutr Sci Vitaminol (Tokyo) 41: 627-634, 1995 
131. Petty MA, Kintz J and DiFrancesco GF: The effects of taurine on atherosclerosis development in cholesterol-fed rabbits. Eur J Pharmacol 180: 119-127, 1990.

132. Murakami S, Sakurai T, Tomoike H, Sakono M, Nasu T and Fukuda N: Prevention of hypercholesterolemia and atherosclerosis in the hyperlipidemia- and atherosclerosis-prone Japanese (LAP) quail by taurine supplementation. Amino Acids 38: 271-278, 2010

133. Murakami S, Nara Y and Yamori Y: Taurine accelerates the regression of hypercholesterolemia in stroke-prone spontaneously hypertensive rats. Life Sci 58: 1643-1651, 1996

134. Yokogoshi H, Mochizuki H, Nanami K, Hida Y, Miyachi F and Oda H: Dietary taurine enhances cholesterol degradation and reduces serum and liver cholesterol concentrations in rats fed a high-cholesterol diet. J Nutr 129: 1705-1712, 1999.

135. Lam NV, Chen W, Suruga K, Nishimura N, Goda T and Yokogoshi $\mathrm{H}$ : Enhancing effect of taurine on CYP7A1 mRNA expression in Hep G2 cells. Amino Acids 30: 43-48, 2006.

136. Bellentani S, Pecorari M, Cordoma P, Marchegiano P, Manenti F, Bosisio E, De Fabiani E and Galli G: Taurine increases bile acid pool size and reduces bile saturation index in the hamster. J Lipid Res 28: 1021-1027, 1987.

137. Yanagita T, Han SY, Hu Y, Nagao K, Kitajima H and Murakami S Taurine reduces the secretion of apolipoprotein B100 and lipids in HepG2 cells. Lipids Health Dis 7: 38, 2008.

138. Ulrich-Merzenich G, Zeitler H, Vetter H and Bhonde RR Protective effects of taurine on endothelial cells impaired by high glucose and oxidized low density lipoproteins. Eur J Nutr 46: 431-438, 2007.

139. Gokce G, Ozsarlak-Sozer G, Oran I, Oktay G, Ozkal S and Kerry Z: Taurine suppresses oxidative stress-potentiated expression of lectin-like oxidized low-density lipoprotein receptor and restenosis in balloon-injured rabbit iliac artery. Clin Exp Pharmacol Physiol 38: 811-818, 2011

140. Matsushima Y, Sekine T, Kondo Y, Sakurai T, Kameo K, Tachibana $\mathrm{M}$ and Murakami S: Effects of taurine on serum cholesterol levels and development of atherosclerosis in spontaneously hyperlipidaemic mice. Clin Exp Pharmacol Physiol 30: 295-299, 2003.

141. Murakami S, Kondo-Ohta Y and Tomisawa K: Improvement in cholesterol metabolism in mice given chronic treatment of taurine and fed a high-fat diet. Life Sci 64: 83-91, 1999.

142. Chen W, Guo JX and Chang P: The effect of taurine on cholesterol metabolism. Mol Nutr Food Res 56: 681-690, 2012.

143. Mochizuki H, Takido J and Yokogoshi H: Effect of dietary taurine on endogenous hypercholesterolemia in rats fed on phenobarbital-containing diets. Biosci Biotechnol Biochem 63 1298-1300, 1999.

144. Mochizuki H, Oda H and Yokogoshi H: Dietary taurine potentiates polychlorinated biphenyl-induced hypercholesterolemia in rats*. J Nutr Biochem 12: 109-115, 2001.

145. Zulli A, Lau E, Wijaya BP, Jin X, Sutarga K, Schwartz GD, Learmont J, Wookey PJ, Zinellu A, Carru C and Hare DL: High dietary taurine reduces apoptosis and atherosclerosis in the left main coronary artery: Association with reduced CCAAT/enhancer binding protein homologous protein and total plasma homocysteine but not lipidemia. Hypertension 53: 1017-1022, 2009.

146. Tan B, Jiang DJ, Huang H, Jia SJ, Jiang JL, Hu CP and Li YJ Taurine protects against low-density lipoprotein-induced endothelial dysfunction by the DDAH/ADMA pathway. Vascul Pharmacol 46: 338-345, 2007

147. Elvevoll EO, Eilertsen KE, Brox J, Dragnes BT, Falkenberg P, Olsen JO, Kirkhus B, Lamglait A and Østerud B: Seafood diets: Hypolipidemic and antiatherogenic effects of taurine and n-3 fatty acids. Atherosclerosis 200: 396-402, 2008.

148. di Wu Q, Wang JH, Fennessy F, Redmond HP and Bouchier-Hayes D: Taurine prevents high-glucose-induced human vascular endothelial cell apoptosis. Am J Physiol 277: C1229-C1238, 1999.

149. Katakawa M, Fukuda N, Tsunemi A, Mori M, Maruyama T, Matsumoto T, Abe M and Yamori Y: Taurine and magnesium supplementation enhances the function of endothelial progenitor cells through antioxidation in healthy men and spontaneously hypertensive rats. Hypertens Res 39: 848-856, 2016.

150. Chang L, Xu J, Yu F, Zhao J, Tang X and Tang C: Taurine protected myocardial mitochondria injury induced by hyperhomocysteinemia in rats. Amino Acids 27: 37-48, 2004.

151. Ghosh J, Das J, Manna P and Sil PC: Taurine prevents arsenic-induced cardiac oxidative stress and apoptotic damage: Role of NF-kappa B, p38 and JNK MAPK pathway. Toxicol Appl Pharmacol 240: 73-87, 2009.
152. Mousavi K, Niknahad H, Ghalamfarsa A, Mohammadi $H$, Azarpira N, Ommati MM and Heidari R: Taurine mitigates cirrhosis-associated heart injury through mitochondrial-dependent and antioxidative mechanisms. Clin Exp Hepatol 6: 207-219, 2020

153. Liu J, Ai Y, Niu X, Shang F, Li Z, Liu H, Li W, Ma W, Chen R, Wei $\mathrm{T}$, et al: Taurine protects against cardiac dysfunction induced by pressure overload through SIRT1-p53 activation. Chem Biol Interact 317: 108972, 2020.

154. Chen G, Nan C, Tian J, Jean-Charles P, Li Y, Weissbach H and Huang XP: Protective effects of taurine against oxidative stress in the heart of MsrA knockout mice. J Cell Biochem 113: 3559-3566, 2012.

155. Rashid K, Das J and Sil PC: Taurine ameliorate alloxan induced oxidative stress and intrinsic apoptotic pathway in the hepatic tissue of diabetic rats. Food Chem Toxicol 51: 317-329, 2013

156. Sevin G, Ozsarlak-Sozer G, Keles D, Gokce G, Reel B, Ozgur HH, Oktay G and Kerry Z: Taurine inhibits increased MMP-2 expression in a model of oxidative stress induced by glutathione depletion in rabbit heart. Eur J Pharmacol 706: 98-106, 2013.

157. Hansen SH, Andersen ML, Cornett C, Gradinaru R and Grunnet N: A role for taurine in mitochondrial function. J Biomed Sci 17 (Suppl 1): S23, 2010.

158. Oriyanhan W, Yamazaki K, Miwa S, Takaba K, Ikeda T and Komeda M: Taurine prevents myocardial ischemia/reperfusion-induced oxidative stress and apoptosis in prolonged hypothermic rat heart preservation. Heart Vessels 20: 278-285, 2005.

159. Sahin MA, Yucel O, Guler A, Doganci S, Jahollari A, Cingoz F, Arslan S, Gamsizkan M, Yaman H and Demirkilic U: Is there any cardioprotective role of Taurine during cold ischemic period following global myocardial ischemia? J Cardiothorac Surg 6: $31,2011$.

160. Venturini A, Ascione R, Lin H, Polesel E, Angelini GD and Suleiman MS: The importance of myocardial amino acids during ischemia and reperfusion in dilated left ventricle of patients with degenerative mitral valve disease. Mol Cell Biochem 330: 63-70, 2009.

161. Xu YJ, Arneja AS, Tappia PS and Dhalla NS: The potential health benefits of taurine in cardiovascular disease. Exp Clin Cardiol 13: 57-65, 2008.

162. Jacobus WE, Tiozzo R, Lugli G, Lehninger AL and Carafoli E: Aspects of energy-linked calcium accumulation by rat heart mitochondria. J Biol Chem 250: 7863-7870, 1975.

163. Rasola A and Bernardi P: Mitochondrial permeability transition in $\mathrm{Ca}(2+)$-dependent apoptosis and necrosis. Cell Calcium 50: 222-233, 2011

164. Zhang Y, Yang L, Yang YJ, Liu XY, Jia JG, Qian JY, Wang KQ, Zuo $\mathrm{J}$ and Ge J: Low-dose taurine upregulates taurine transporter expression in acute myocardial ischemia. Int $\mathrm{J}$ Mol Med 31: 817-824, 2013.

165. Schaffer S, Solodushko V and Azuma J: Taurine-deficient cardiomyopathy: Role of phospholipids, calcium and osmotic stress. In: Taurine 4. Advances in Experimental Medicine and Biology. Della Corte L, Huxtable RJ, Sgaragli G and Tipton KF (eds). Vol 483. Springer, Boston, MA, pp57-69, 2002.

166. Bagchi D, Wetscher GJ, Bagchi M, Hinder PR, Perdikis G, Stohs SJ, Hinder RA and Das DK: Interrelationship between cellular calcium homeostasis and free radical generation in myocardial reperfusion injury. Chem Biol Interact 104: 65-85, 1997.

167. Grace PA: Ischaemia-reperfusion injury. Br J Surg 81: 637-647, 1994.

168. Lemasters JJ, Nieminen AL, Qian T, Trost LC and Herman B: The mitochondrial permeability transition in toxic, hypoxic and reperfusion injury. Mol Cell Biochem 174: 159-165, 1997.

169. Kaplan B, Aricioglu A, Erbas D, Erbas S and Turkozkan N: The effects of taurine on perfused heart muscle malondialdehyde levels. Gen Pharmacol 24: 1411-1413, 1993

170. Ramila KC, Jong CJ, Pastukh V, Ito T, Azuma J and Schaffer SW: Role of protein phosphorylation in excitation-contraction coupling in taurine deficient hearts. Am J Physiol-Heart Circ Physiol 308: H232-H239, 2015.

171. Modi P and Suleiman MS: Myocardial taurine, development and vulnerability to ischemia. Amino Acids 26: 65-70, 2004.

172. Tricarico D, Barbieri M and Camerino DC: Taurine blocks ATP-sensitive potassium channels of rat skeletal muscle fibres interfering with the sulphonylurea receptor. Br J Pharmacol 130: $827-834,2000$. 
173. TricaricoD,Barbieri Mand Conte CamerinoD: Voltage-dependent antagonist/agonist actions of taurine on $\mathrm{Ca}(2+)$-activated potassium channels of rat skeletal muscle fibers. J Pharmacol Exp Ther 298: 1167-1171, 2001

174. Shimada K, Jong CJ, Takahashi K and Schaffer SW: Role of ROS Production and Turnover in the Antioxidant Activity of Taurine. In: Taurine 9. Marcinkiewicz J and Schaffer SW (eds). pp581-96, 2015.

175. Takatani T, Takahashi K, Uozumi Y, Shikata E, Yamamoto Y, Ito T, Matsuda T, Schaffer SW, Fujio Y and Azuma J: Taurine inhibits apoptosis by preventing formation of the Apaf-1/caspase-9 apoptosome. Am J Physiol Cell Physiol 287: C949-C953, 2004.

176. Li Y, Arnold JM, Pampillo M, Babwah AV and Peng T: Taurine prevents cardiomyocyte death by inhibiting NADPH oxidase-mediated calpain activation. Free Radic Biol Med 46 $51-61,2009$

177. Ahmadi S and Mehranjani MS: Taurine improves follicular survival and function of mice ovarian grafts through increasing CD31 and GDF9 expression and reducing oxidative stress and apoptosis. Eur J Pharmacol 903: 174134, 2021

178. Ito T, Yoshikawa N, Schaffer SW and Azuma J: Tissue taurine depletion alters metabolic response to exercise and reduces running capacity in mice. J Amino Acids 2014: 964680, 2014.

179. Bakker AJ and Berg HM: Effect of taurine on sarcoplasmic reticulum function and force in skinned fast-twitch skeletal muscle fibres of the rat. J Physiol 538: 185-194, 2002

180. Thirupathi A, Pinho RA, Baker JS, István B and Gu Y: Taurine reverses oxidative damages and restores the muscle function in overuse of exercised muscle. Front Physiol 11: 582449, 2020.

181. Dutka TL, Lamboley CR, Murphy RM and Lamb GD: Acute effects of taurine on sarcoplasmic reticulum $\mathrm{Ca}^{2+}$ accumulation and contractility in human type I and II skeletal muscle fibers. J Appl Physiol 117: 797-805, 1985.

182. De Luca A, Pierno S and Camerino DC: Taurine: The appeal of a safe amino acid for skeletal muscle disorders. J Transl Med 13, 243, 2015

183. De Luca A, Pierno S and Camerino DC: Effect of taurine depletion on excitation-contraction coupling and Cl-conductance of rat skeletal muscle. Eur J Pharmacol 296: 215-222, 1996

184. Jentsch TJ: CLC chloride channels and transporters: From genes to protein structure, pathology and physiology. Crit Rey Biochem Mol Biol 43: 3-36, 2008.

185. Hamilton EJ, Berg HM, Easton CJ and Bakker AJ: The effect of taurine depletion on the contractile properties and fatigue in fast-twitch skeletal muscle of the mouse. Amino Acids 31 273-278, 2006.

186. Tallis J, Higgins MF, Cox VM, Duncan MJ and James RS: Does a physiological concentration of taurine increase acute muscle power output, time to fatigue, and recovery in isolated mouse soleus (slow) muscle with or without the presence of caffeine? Can J Physiol Pharmacol 92: 42-49, 2014.

187. Yatabe Y, Miyakawa S, Miyazaki T, Matsuzaki Y and Ochiai N: Effects of taurine administration in rat skeletal muscles on exercise. J Orthop Sci 8: 415-419, 2003

188. Ohmori H, Matsumura M, Komine S, Kobayashi H, Kobayashi Y, Shiromoto J and Miyakawa S: The production of a rat model that inhibits phosphoenolpyruvate carboxykinase (PEPCK), a rate-limiting enzyme of hepatic gluconeogenesis. In: Taurine 11 Advances in Experimental Medicine and Biology. Hu J, Piao F, Schaffer SW, El Idrissi A and Wu JY (eds). Vol 1155. Springer, Singapore, pp113-118, 2019.

189. Zachariah Tom R, Garcia-Roves PM, Sjögren RJ, Jiang LQ, Holmström MH, Deshmukh AS, Vieira E, Chibalin AV, Björnholm M and Zierath JR: Effects of AMPK activation on insulin sensitivity and metabolism in leptin-deficient ob/ob mice. Diabetes 63: 1560-1571, 2014.

190. Beloshapka AN, de Godoy MR, Carter RA, Fascetti AJ, Yu Z, McIntosh BJ, Swanson KS and Buff PR: Longitudinal changes in blood metabolites, amino acid profile, and oxidative stress markers in American foxhounds fed a nutrient-fortified diet. J Anim Sci 96: 930-940, 2018

191. Dawson R Jr, Biasetti M, Messina S and Dominy J: The cytoprotective role of taurine in exercise-induced muscle injury. Amino Acids 22: 309-324, 2002

192. Silva LA, Silveira PC, Ronsani MM, Souza PS, Scheffer D, Vieira LC, Benetti M, De Souza CT and Pinho RA: Taurine supplementation decreases oxidative stress in skeletal muscle after eccentric exercise. Cell Biochem Funct 29: 43-49, 2011.

193. Marcinkiewicz J: Taurine bromamine: A new therapeutic option in inflammatory skin diseases. Pol Arch Med Wewn 119: 673-676, 2009.
194. Kato T, Okita S, Wang S, Tsunekawa M and Ma N: The effects of Taurine administration against inflammation in heavily exercised skeletal muscle of rats. In: Taurine 9. Advances in Experimental Medicine and Biology. Marcinkiewicz J and Schaffer SW (eds). Vol 803. Springer, New York, NY, pp773-784, 2015.

195. Sugiura H, Okita S, Kato T, Naka T, Kawanishi S, Ohnishi S, Oshida Y amd Ma N: Protection by taurine against INOS-dependent DNA damage in heavily exercised skeletal muscle by inhibition of the NF- $\mathrm{B}$ signaling pathway. In: Taurine 8. Advances in Experimental Medicine and Biology. El Idrissi A and L'Amoreaux WJ (eds). Vol 775. Springer, New York, NY, pp237-246, 2013.

196. Moyes CD: Controlling muscle mitochondrial content. J Exp Biol 206: 4385-4391, 2003

197. Nikolaidis MG and Mougios V: Effects of exercise on the fatty-acid composition of blood and tissue lipids. Sports Med 34: 1051-1057, 2004.

198. Nikolaidis MG, Petridou A and Mougios V: Comparison of the phospholipid and triacylglycerol fatty acid profile of rat serum, skeletal muscle and heart. Physiol Res 55: 259-265, 2006.

199. Imagawa TF, Hirano I, Utsuki K, Horie M, Naka A, Matsumoto K and Imagawa S: Caffeine and taurine enhance endurance performance. Int J Sports Med 30: 485-488, 2009.

200. Mikami N, Hosokawa M and Miyashita K: Dietary combination of fish oil and taurine decreases fat accumulation and ameliorates blood glucose levels in type 2 diabetic/obese KK-A(y) mice. J Food Sci 77: H114-H120, 2012

201. Ra SG, Miyazaki T, Ishikura K, Nagayama H, Komine S, Nakata Y, Maeda S, Matsuzaki Y and Ohmori H: Combined effect of branched-chain amino acids and taurine supplementation on delayed onset muscle soreness and muscle damage in high-intensity eccentric exercise. J Int Soc Sports Nutr 10: 51, 2013.

202. Galloway SD, Talanian JL, Shoveller AK, Heigenhauser GJ and Spriet LL: Seven days of oral taurine supplementation does not increase muscle taurine content or alter substrate metabolism during prolonged exercise in humans. J Appl Physiol (1985) 105: 643-651, 2008.

203. D'Antona G, Nabavi SM, Micheletti P, Di Lorenzo A, Aquilani R, Nisoli E, Rondanelli M and Daglia M: Creatine, L-carnitine, and $\omega 3$ polyunsaturated fatty acid supplementation from healthy to diseased skeletal muscle. Biomed Res Int 2014: 613890, 2014

204. Rutherford JA, Spriet LL and Stellingwerff T: The effect of acute taurine ingestion on endurance performance and metabolism in well-trained cyclists. Int J Sport Nutr Exerc Metab 20: 322-329, 2010

205. Balshaw TG, Bampouras TM, Barry TJ and Sparks SA: The effect of acute taurine ingestion on 3-km running performance in trained middle-distance runners. Amino Acids 44: 555-561, 2013.

206. da Silva LA, Tromm CB, Bom KF, Mariano I, Pozzi B, da Rosa GL, Tuon T, da Luz G, Vuolo F, Petronilho F, et al: Effects of taurine supplementation following eccentric exercise in young adults. Appl Physiol Nutr Metab 39: 101-104, 2014.

207. Ra SG, Choi Y, Akazawa N, Kawanaka K, Ohmori H and Maeda S: Effects of taurine supplementation on vascular endothelial function at rest and after resistance exercise. In: Taurine 11. Advances in Experimental Medicine and Biology. Hu J, Piao F, Schaffer SW, El Idrissi A and Wu JY (eds). Vol 1155. Springer, Singapore, pp407-414, 2019

208.Zhang M, Izumi I, Kagamimori S, Sokejima S, Yamagami T, Liu Z and Qi B: Role of taurine supplementation to prevent exercise-induced oxidative stress in healthy young men. Amino Acids 26: 203-207, 2004

209. Chupel MU, Minuzzi LG, Furtado GE, Santos ML, Ferreira JP, Filaire E and Teixeira AM: Taurine supplementation reduces myeloperoxidase and matrix-metalloproteinase-9 levels and improves the effects of exercise in cognition and physical fitness in older women. Amino Acids 53: 333-435, 2021.

210. De Paepe B, Martin JJ, Herbelet S, Jimenez-Mallebrera C, Iglesias E, Jou C, Weis J and De Bleecker JL: Activation of osmolyte pathways in inflammatory myopathy and Duchenne muscular dystrophy points to osmoregulation as a contributing pathogenic mechanism. Lab Invest 96: 872-884, 2016

211. Pierno S, Liantonio A, Camerino GM, De Bellis M, Cannone M, Gramegna G, Scaramuzzi A, Simonetti S, Nicchia GP, Basco D, et al: Potential benefits of taurine in the prevention of skeletal muscle impairment induced by disuse in the hindlimb-unloaded rat. Amino Acids 43: 431-445, 2012. 
212. Uozumi Y, Ito T, Hoshino Y, Mohri T, Maeda M, Takahashi K, Fujio Y and Azuma J: Myogenic differentiation induces taurine transporter in association with taurine-mediated cytoprotection in skeletal muscles. Biochem J 394: 699-706, 2006.

213. Terrill JR, Grounds MD and Arthur PG: Taurine deficiency, synthesis and transport in the mdx mouse model for Duchenne muscular dystrophy. Int J Biochem Cell Biol 66: 141-148, 2015.

214. Cozzoli A, Nico B, Sblendorio VT, Capogrosso RF, Dinardo MM Longo V, Gagliardi S, Montagnani M and De Luca A: Enalapril treatment discloses an early role of angiotensin II in inflammation- and oxidative stress-related muscle damage in dystrophic mdx mice. Pharmacol Res 64: 482-492, 2011.

215. Jaeschke H: Reactive oxygen and mechanisms of inflammatory liver injury. J Gastroenterol Hepatol 15: 718-724, 2000.

216. Warskulat U, Borsch E, Reinehr R, Heller-Stilb B, Mönnighoff I, Buchczyk D, Donner M, Flögel U, Kappert G, Soboll S, et al: Chronic liver disease is triggered by taurine transporter knockout in the mouse. FASEB J 20: 574-576, 2006.

217. Chen X, Sebastian BM, Tang H, McMullen MM, Axhemi A, Jacobsen DW and Nagy LE: Taurine supplementation prevents ethanol-induced decrease in serum adiponectin and reduces hepatic steatosis in rats. Hepatology 49: 1554-1562, 2009.

218. Goc Z, Kapusta E, Formicki G, Martiniaková M and Omelka R: Effect of taurine on ethanol-induced oxidative stress in mouse liver and kidney. Chin J Physiol 62: 148-156, 2019.

219. Lin CJ, Chiu CC, Chen YC, Chen ML, Hsu TC and Tzang BS: Taurine attenuates hepatic inflammation in chronic alcohol-fed rats through inhibition of TLR4/MyD88 signaling. J Med Food 18: 1291-1298, 2015

220. Murakami S, Ono A, Kawasaki A, Takenaga T and Ito T: Taurine attenuates the development of hepatic steatosis through the inhibition of oxidative stress in a model of nonalcoholic fatty liver disease in vivo and in vitro. Amino Acids 50: 1279-1288, 2018.

221. Zhang Z, Liu D, Yi B, Liao Z, Tang L, Yin D and He M: Taurine supplementation reduces oxidative stress and protects the liver in an iron-overload murine model. Mol Med Rep 10: 2255-2262, 2014

222. Choi MJ and Jung YJ: Effects of taurine and vitamin d on antioxidant enzyme activity and lipids profiles in rats fed diet deficien calcium. In: Taurine 10. Advances in Experimental Medicine and Biology. Lee DH, Schaffer SW, Park E and Kim HW (eds). Vol 975. Springer, Dordrecht, pp1081-1092, 2017.

223. Abdel-Daim MM, Dessouki AA, Abdel-Rahman HG, Eltaysh R and Alkahtani S: Hepatorenal protective effects of taurine and $\mathrm{N}$-acetylcysteine against fipronil-induced injuries: The antioxidant status and apoptotic markers expression in rats. Sci Total Environ 650: 2063-2073, 2019.

224. Hoang MH, Jia Y, Jun H, Lee JH, Hwang KY, Choi DW, Um SJ, Lee BY, You SG and Lee SJ: Taurine is a liver X receptor- $\alpha$ ligand and activates transcription of key genes in the reverse cholesterol transport without inducing hepatic lipogenesis. Mol Nutr Food Res 56: 900-911, 2012.

225. Geyeregger R, Zeyda M and Stulnig TM: Liver X receptors in cardiovascular and metabolic disease. Cell Mol Life 63 524-539, 2006.

226. Cao PJ, Jin YJ, Li ME, Zhou R and Yang MZ: PGC-1 $\alpha$ may associated with the anti-obesity effect of taurine on rats induced by arcuate nucleus lesion. Nutr Neurosci 19: 86-93, 2016.

227. Mizushima S, Nara Y, Sawamura M and Yamori Y: Effects of oral taurine supplementation on lipids and sympathetic nerve tone. In: Taurine 2. Advances in Experimental Medicine and Biology. Huxtable RJ, Azuma J, Kuriyama K, Nakagawa M and Baba A (eds). Vol 403. Springer, Boston, MA, pp615-622, 1996.

228. Zhang M, Bi LF, Fang JH, Su XL, Da GL, Kuwamori T and Kagamimori S: Beneficial effects of taurine on serum lipids in overweight or obese non-diabetic subjects. Amino Acids 26 : 267-271, 2004.

229. Miyazaki T, Karube M, Matsuzaki Y, Ikegami T, Doy M, Tanaka $\mathrm{N}$ and Bouscarel B: Taurine inhibits oxidative damage and prevents fibrosis in carbon tetrachloride-induced hepatic fibrosis. J Hepatol 43: 117-125, 2005.

230. Abd-Elhakim YM, Ghoneim MH,Ebraheim LLM and Imam TS Taurine and hesperidin rescues carbon tetrachloride-triggered testicular and kidney damage in rats via modulating oxidative stress and inflammation. Life Sci 254: 117782, 2020.

231. Burlacu A, Genovesi S, Ortiz A, Combe C, Basile C, Schneditz D, van der Sande F, Popa GT, Morosanu C and Covic A: Pros and cons of antithrombotic therapy in end-stage kidney disease: A 2019 update. Nephrol Dial Transplant 34: 923-933, 2019.
232. Ijiri Y, Ikarugi H, Tamura Y, Ura M, Morishita M, Hamada A, Mori M, Mori H, Yamori Y, Ishii $\mathrm{H}$ and Yamamoto $\mathrm{J}$ : Antithrombotic effect of taurine in healthy Japanese people may be related to an increased endogenous thrombolytic activity. Thromb Res 131: 158-161, 2013.

233. Lee WM: Acetaminophen toxicity: Changing perceptions on a social/medical issue. Hepatology 46: 966-970, 2007.

234. Bessems JG and Vermeulen NP: Paracetamol (acetaminophen)induced toxicity: Molecular and biochemical mechanisms, analogues and protective approaches. Crit Rev Toxicol 31: $55-138,2001$.

235. Jaeschke H, Knight TR and Bajt ML: The role of oxidant stress and reactive nitrogen species in acetaminophen hepatotoxicity. Toxicol Lett 144: 279-288, 2003.

236. Hinson JA, Roberts DW and James LP: Mechanisms of acetaminophen-induced liver necrosis. In: Adverse Drug Reactions. Handbook of Experimental Pharmacology. Uetrecht J (ed). Vol 196. Springer, Berlin, pp369-405, 2010.

237. Acharya M and Lau-Cam CA: Comparison of the protective actions of $\mathrm{N}$-acetylcysteine, hypotaurine and taurine against acetaminophen-induced hepatotoxicity in the rat. J Biomed Sci 17 (Suppl 1): S35, 2010

238. Acharya M and Lau-Cam CA: Comparative evaluation of the effects of taurine and thiotaurine on alterations of the cellular redox status and activities of antioxidant and glutathione-related enzymes by acetaminophen in the rat. In: Taurine 8. Advances in Experimental Medicine and Biology. El Idrissi A and L'Amoreaux WJ (eds). Vol 776. Springer, New York, NY, pp199-215, 2013.

239. Ghandforoush-Sattari M and Mashayekhi S: Evaluation of taurine as a biomarker of liver damage in paracetamol poisoning. Eur J Pharmacol 581: 171-176, 2008.

240. Boşgelmez İI, Söylemezoğlu T and Güvendik G: The protective and antidotal effects of taurine on hexavalent chromium-induced oxidative stress in mice liver tissue. Biol Trace Elem Res 125: 46-58, 2008

241. Tabassum H, Rehman H, Banerjee BD, Raisuddin S and Parvez S: Attenuation of tamoxifen-induced hepatotoxicity by taurine in mice. Clin Chim Acta 370: 129-136, 2006.

242. Patrick L: Lead toxicity part II: The role of free radical damage and the use of antioxidants in the pathology and treatment of lead toxicity. Altern Med Rev 11: 114-127, 2006.

243. Hwang DF, Wang LC and Cheng HM: Effect of taurine on toxicity of copper in rats. Food Chem Toxicol 36: 239-244, 1998.

244. Hwang D and Wang LC: Effect of taurine on toxicity of cadmium in rats. Toxicology 167: 173-180, 2001.

245. Jamshidzadeh A, Heidari R, Abasvali M,Zarei M, Ommati MM, Abdoli N, Khodaei F, Yeganeh Y, Jafari F, Zarei A, et al: Taurine treatment preserves brain and liver mitochondrial function in a rat model of fulminant hepatic failure and hyperammonemia. Biomed Pharmacother 86: 514-520, 2017.

246. Doğru-Abbasoğlu S, Kanbağli O, Balkan J, Cevikbaş U, Aykaç-Toker $\mathrm{G}$ and Uysal M: The protective effect of taurine against thioacetamide hepatotoxicity of rats. Hum Exp Toxicol 20: 23-27, 2001

247. Bardach AE, Ciapponi A, Soto N, Chaparro MR, Calderon M, Briatore A, Cadoppi N, Tassara R and Litter MI: Epidemiology of chronic disease related to arsenic in Argentina: A systematic review. Sci Total Environ 538: 802-816, 2015.

248. Li S, Yang L, Dong G and Wang X: Taurine protects mouse liver against arsenic-induced apoptosis through JNK pathway. In: Taurine 10. Advances in Experimental Medicine and Biology. Lee DH, Schaffer SW and Park E, Kim HW (eds). Vol 975. Springer, Dordrecht, pp855-862, 2017.

249. Taranukhin AG, Taranukhina EY, Saransaari P, Pelto-Huikko M, Podkletnova IM and Oja SS: Taurine protects cerebellar neurons of the external granular layer against ethanol-induced apoptosis in 7-day-old mice. Amino Acids 43: 1705-1711, 2012

250. Lau A, Zheng Y, Tao S, Wang H, Whitman SA, White E and Zhang DD: Arsenic inhibits autophagic flux, activating the Nrf2-Keap1 pathway in a p62-dependent manner. Mol Cell Biol 33: 2436-2446, 2013.

251. Bai J, Yao X, Jiang L, Zhang Q, Guan H, Liu S, Wu W, Qiu T, Gao N, Yang L, et al: Taurine protects against As2O3-induced autophagy in livers of rat offsprings through PPAR $\gamma$ pathway. Sci Rep 6: 27733, 2016

252. Qiu T, Pei P, Yao X, Jiang L, Wei S, Wang Z, Bai J, Yang G, Gao N, Yang L, et al: Taurine attenuates arsenic-induced pyroptosis and nonalcoholic steatohepatitis by inhibiting the autophagic-inflammasomal pathway. Cell Death Dis 9: 946, 2018 . 
253. Flora SJS, Chouhan S, Kannan GM, Mittal M and Swarnkar H: Combined administration of taurine and monoisoamyl DMSA protects arsenic induced oxidative injury in rats. Oxid Med Cell Longev 1: 39-45, 2008

254. Cao W, Zhou Y, Li Y, Zhang X, He M, Zang N, Zhou Y and Liao M: iTRAQ-based proteomic analysis of combination therapy with taurine, epigallocatechin gallate, and genistein on carbon tetrachloride-induced liver fibrosis in rats. Toxicol Lett 232: 233-245, 2015.

255. El-Houseini ME, El-Agoza IA, Sakr MM and El-Malky GM: Novel protective role of curcumin and taurine combination against experimental hepatocarcinogenesis. Exp Ther Med 13: 29-36, 2017

256. Abd-Rabou AA, Zoheir KMA and Ahmed HH: Potential impact of curcumin and taurine on human hepatoma cells using Huh-7 cell line. Clin Biochem 45: 1519-1521, 2012.

257. Pan MH, Yang G, Li S, Li MY, Tsai ML, Wu JC, Badmaev V, Ho CT and Lai CS: Combination of citrus polymethoxyflavones, green tea polyphenols, and Lychee extracts suppresses obesity and hepatic steatosis in high-fat diet induced obese mice. Mol Nutr Food Res 61, 2017.

258. Balkan J, Kanbagli Ö, Hatipoglu A, Küçük M, Çevikbas U, Aykaç-Toker $\mathrm{G}$ and Uysal M: Improving effect of dietary taurine supplementation on the oxidative stress and lipid levels in the plasma, liver and aorta of rabbits fed on a high-cholesterol diet. Biosci Biotechnol Biochem 66: 1755-1758, 2002.

259. Cetiner M, Sener G, Sehirli AO, Ekşioğlu-Demiralp E, Ercan F, Sirvanci S, Gedik N, Akpulat S, Tecimer T and Yeğen BC: Taurine protects against methotrexate-induced toxicity and inhibits leukocyte death. Toxicol Appl Pharmacol 209: 39-50, 2005.

260.Kalaz EB, Çoban J, Aydın AF, Doğan-Ekici I, DoğruAbbasoğlu S, Öztezcan S and Uysal M: Carnosine and taurine treatments decreased oxidative stress and tissue damage induced by D-galactose in rat liver. J Physiol Biochem 70: 15-25, 2014.

261. Shi X, Yao D and Chen C: Identification of N-acetyltaurine as a novel metabolite of ethanol through metabolomics-guided biochemical analysis. J Biol Chem 287: 6336-6349, 2012.

262. Heidari R, Babaei H and Eghbal MA: Amodiaquine-induced toxicity in isolated rat hepatocytes and the cytoprotective effects of taurine and/or N-acetyl cysteine. Res Pharm Sci 9: 97-105, 2014

263. Timbrell JA and Waterfield CJ: Changes in taurine as an indicator of hepatic dysfunction and biochemical perturbations. In: Taurine 2. Advances in Experimental Medicine and Biology. Huxtable RJ, Azuma J, Kuriyama K, Nakagawa M and Baba A (eds). Vol 403. Springer, Boston, MA, pp125-134, 1996.

264. Gordon RE, Park E, Laskin D and Schuller-Levis GB: Taurine protects rat bronchioles from acute ozone exposure: A freeze fracture and electron microscopic study. Exp Lung Res 24 659-674, 1998.

265. Venkatachalam S, Kuppusamy P, Kuppusamy B and Dhanapal S: The potency of essential nutrient taurine on boosting the antioxidant status and chemopreventive effect against benzo (a) pyrene induced experimental lung cancer. Biomed Prev Nutr 4: 251-255, 2014.
266. Gurujeyalakshmi G, Wang Y and Giri SN: Suppression of bleomycin-induced nitric oxide production in mice by taurine and niacin. Nitric Oxide 4: 399-411, 2000.

267. Wang Q, Hollinger MA and Giri SN: Attenuation of amiodarone-induced lung fibrosis and phospholipidosis in hamsters by taurine and/or niacin treatment. J Pharmacol Exp Ther 262: $127-132,1992$

268. Izumi K, Nagata R, Motoya T, Yamashita J, Hirokane T, Nagata T, Satoh Y, Sawada Y, Ishibashi M, Yoshida H, et al: Preventive effect of taurine against acute paraquat intoxication in beagles. Jpn J Pharmacol 50: 229-233, 1989.

269. Li S, Wang J, Wei BK, Dong G and Wang X: Protective effect of taurine on paraquat-induced lung epithelial cell injury. In: Taurine 11. Advances in Experimental Medicine and Biology. Hu J, Piao F, Schaffer SW, El Idrissi A and Wu JY (eds). Vol 1155. Springer, Singapore, pp739-746, 2019.

270. Khalili Fard J, Hamzeiy H, Sattari M and Eghbal MA: Protective roles of $\mathrm{N}$-acetyl cysteine and/or taurine against sumatriptan-induced hepatotoxicity. Adv Pharm Bull 6: 627-637, 2016.

271. Gordon RE, Shaked AA and Solano DF: Taurine protects hamster bronchioles from acute $\mathrm{NO}_{2}$-induced alterations. A histologic, ultrastructural, and freeze-fracture study. Am J Pathol 125: 585-600, 1986.

272. Jeon SH, Lee MY, Rahman MM, Kim SJ, Kim GB, Park SY, Hong CU, Kim SZ, Kim JS and Kang HS: The antioxidant, taurine reduced lipopolysaccharide (LPS)-induced generation of ROS, and activation of MAPKs and Bax in cultured pneumocytes. Pulm Pharmacol Ther 22: 562-566, 2009.

273. Das J, Ghosh J, Manna P, Sinha M and Sil PC: Taurine protects rat testes against $\mathrm{NaAsO}(2)$-induced oxidative stress and apoptosis via mitochondrial dependent and independent pathways. Toxicol Lett 187: 201-210, 2009.

274. Meizel S: Molecules that initiate or help stimulate the acrosome reaction by their interaction with the mammalian sperm surface. Am J Anat 174: 285-302, 1985.

275. Aly HA and Khafagy RM: Taurine reverses endosulfan-induced oxidative stress and apoptosis in adult rat testis. Food Chem Toxicol 64: 1-9, 2014.

276. Azab SS, kamel I, Ismail NN, El Din Hosni H and El Fatah MA: The defensive role of taurine against gonadotoxicity and testicular apoptosis effects induced by cisplatin in rats. J Infect Chemother 26: 51-57, 2020.

277. Yahyavy S, Valizadeh A, Saki G and Khorsandi L: Taurine induces autophagy and inhibits oxidative stress in mice Leydig cells. JBRA Assist Reprod 24: 250-256, 2020.

278. Kalender S, Apaydin FG and Kalender Y: Testicular toxicity of orally administrated bisphenol $\mathrm{A}$ in rats and protective role of taurine and curcumin. Pak J Pharm Sci 32: 1043-1047, 2019.

This work is licensed under a Creative Common Attribution-NonCommercial-NoDerivatives 4.0 International (CC BY-NC-ND 4.0) License. 